\title{
Brassinosteroids, the Sixth Class of Phytohormones: A Molecular View from the Discovery to Hormonal Interactions in Plant Development and Stress Adaptation
}

\author{
Ana Laura G. L. Peres ${ }^{1}$, José Sérgio Soares ${ }^{1}$ (D), Rafael G. Tavares ${ }^{2}$, Germanna Righetto ${ }^{1}$, \\ Marco A. T. Zullo ${ }^{3}$, N. Bhushan Mandava ${ }^{4}$ and Marcelo Menossi ${ }^{1, *(D)}$ \\ 1 Functional Genome Laboratory, Department of Genetics, Evolution, Microbiology and Immunology, \\ Institute of Biology, State University of Campinas, Campinas 13083-970, Brazil; \\ analaura@lgf.ib.unicamp.br (A.L.G.L.P.); zesergio@lgf.ib.unicamp.br (J.S.S.); \\ germanna@lgf.ib.unicamp.br (G.R.) \\ 2 Center for Tropical Crops and Biocommodities, Queensland University of Technology, \\ Brisbane, QLD 400, Australia; rafael@lgf.ib.unicamp.br \\ 3 Laboratory of Phytochemistry, Agronomic Institute, Campinas 13020-902, Brazil; mzullo@uol.com.br \\ 4 Mandava Associates, LLC, 1050 Connecticut Avenue, N.W. Suite 500, Washington, DC 20036, USA; \\ bhushan.mandava@verizon.net \\ * Correspondence: menossi@lgf.ib.unicamp.br; Tel.: +55-19-3521-6236
}

Received: 28 September 2018; Accepted: 16 November 2018; Published: 15 January 2019

\begin{abstract}
Phytohormones are natural chemical messengers that play critical roles in the regulation of plant growth and development as well as responses to biotic and abiotic stress factors, maintaining plant homeostasis, and allowing adaptation to environmental changes. The discovery of a new class of phytohormones, the brassinosteroids (BRs), almost 40 years ago opened a new era for the studies of plant growth and development and introduced new perspectives in the regulation of agronomic traits through their use in agriculture. BRs are a group of hormones with significant growth regulatory activity that act independently and in conjunction with other phytohormones to control different BR-regulated activities. Genetic and molecular research has increased our understanding of how BRs and their cross-talk with other phytohormones control several physiological and developmental processes. The present article provides an overview of BRs' discovery as well as recent findings on their interactions with other phytohormones at the transcriptional and post-transcriptional levels, in addition to clarifying how their network works to modulate plant growth, development, and responses to biotic and abiotic stresses.
\end{abstract}

Keywords: brassinosteroids; plant hormones; hormonal cross-talk

\section{Introduction}

In the first years of the 20th Century, the only known plant hormones with recognized roles in development were indole-acetic acid and gibberellic acid. Some early experiments demonstrated that the application of the spores or pollen of some plants to the stigmas of other species promotes the development of parthenocarpic fruits therein. Even pollen extracts [1], and some growth-promoting chemicals [2], were shown to promote parthenocarpy. When applied to the first internode of intact bean plants, ethereal extracts from corn pollen caused pronounced elongation compared to control and even plants treated with natural or synthetic auxins [3]. The same effect was obtained with extracts prepared from immature bean seeds [4]. It was further shown that Brassica napus and Alnus 
glutinosa pollens contain some plant growth regulators, termed brassins, considered plant hormones as they were supposed to be "specific translocatable organic compounds isolated from a plant and have induced measurable growth control when applied in minute amounts to another plant" [5]. The pollen extracts of many other plant species showed the same effects [6], but it was not possible at that time to attribute the physiological effects observed by the application of brassins to any known compound. After a time-consuming and expensive multidisciplinary effort [7] -that involved the processing of at least 400 pounds of rape pollen by a newly-developed method for obtaining brassins [8] as well as physiological and agronomical assays with the active fractions-brassinolide (BL) (Figure 1) [9] was identified as the compound responsible for the different physiological effects produced by brassins. The first syntheses of BL $[10,11]$ and similar compounds [12-15] were soon reported, and the development of a micromethod for their detection [16] (from which many others derived $[17,18])$ revealed compounds resembling BL in many plant species. In the coming years the isolation of many other compounds with structures similar to BL gave rise to the family of brassinosteroids (BRs) [19-24], defined as the "3-oxygenated (20 $\beta$ )-5 $\alpha$-cholestane-22 $\alpha, 23 \alpha$-diols or their derived compounds isolated from plants, bearing additional alkyl or oxy substituents" [25], now recognized as the sixth class of plant hormones. This class of phytohormones is represented by more than 60 compounds (Figure 1) that have been isolated or detected from more than 100 plant species, from algae to angiosperms, revealing their ubiquitous distribution in the plant kingdom $[25,26]$.

Simultaneous to efforts being made to isolate the active principle(s) of the brassins, experiments were being conducted to verify their possible beneficial effects on crops $[27,28]$ as well as to determine their hormonal functions [29-31]. The first syntheses of BL [10,11], 28-homobrassinolide [12], 24-epibrassinolide [13], and other BRs allowed pure compounds to be assayed by the methods used for testing other established plant hormones, such as auxins [32,33], cytokinin, and gibberellin [34,35]. It also allowed their interactions with other plant hormones to be tested [36,37], providing a solid basis for understanding their actions in plant growth and development [38-41], including the role of BL in the germination and growth of pollen tubes [42]. Molecular analyses of BRs' action soon appeared [43], and the discovery of BR-deficient mutants [44], BR-signaling mutants [45], and of BR biosynthesis inhibitors $[46,47]$ made it possible to further determine their mechanisms of action at the molecular level. The elucidation of the BL structure and its receptor kinase BRASSINOSTEROID INSENSITIVE 1 (BRI1) provided insight into the recognition of BRs by their receptor and the activation of the BL-BRI1 complex [48,49]. The evolution of the research into the physiological and biochemical aspects of brassinosteroids is reviewed elsewhere [50].

Previous and recent studies have indicated how the cross-talk between BRs and other phytohormones might contribute to the regulation of an extensive spectrum of biological processes. The present review provides an overview of the current knowledge on the cross-talk between brassinosteroids and other phytohormones, such as auxin (AUX), gibberellins (GAs), cytokinins (CKs), ethylene (ET), abscisic acid (ABA), jasmonic acid (JA), and salicylic acid (SA) at the transcriptional and post-transcriptional levels, as well as how their networks may contribute to the modulation of plant growth, development, and other biological processes. Our major objective is to provide a clear understanding of how BR in conjunction with other phytohormones controls different activities in plant metabolism. 


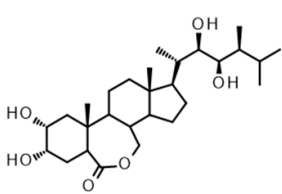

Brassinolide

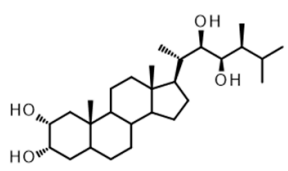

6-Deoxocastasterone

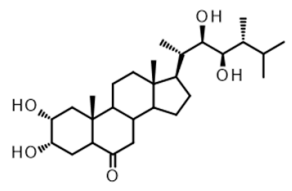

24-Epicastasterone

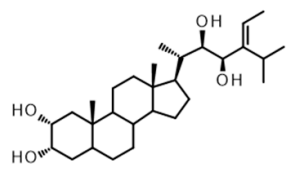

6-Deoxo-28-homodolichosterone

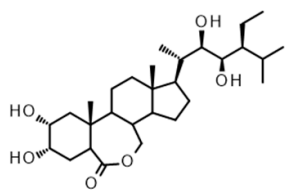

28-Homobrassinolide

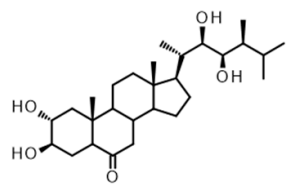

3-Epicastasterone

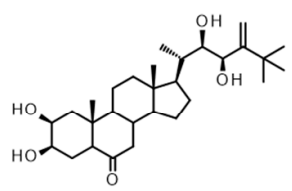

2,3-Diepi-25-methyldolichosterone

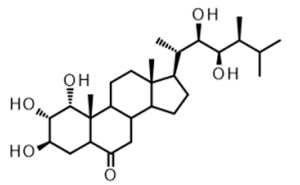

1 $\alpha$-Hydroxy-3-epicastasterone

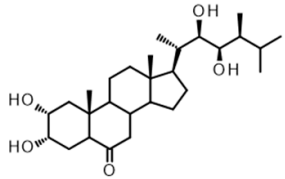

Castasterone

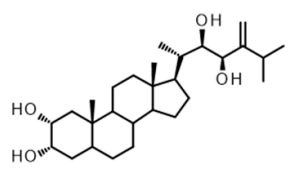

6-Deoxodolichosterone

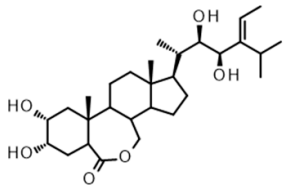

28-Homodolicholide

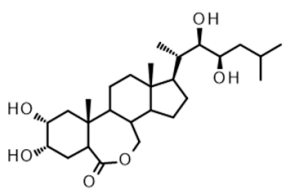

28-Norbrassinolide

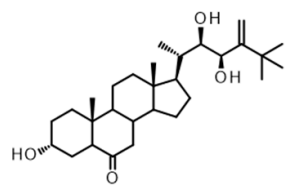

2-Deoxy-25-methyldolichosterone

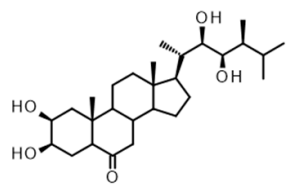

2,3-Diepicastasterone

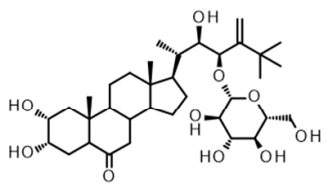

23-O- $\beta$-D-Glucopyranosyl-25methyldolichosterone

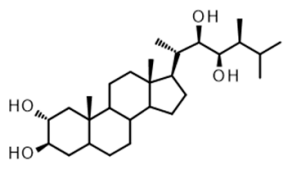

3-Epi-6-deoxocastasterone

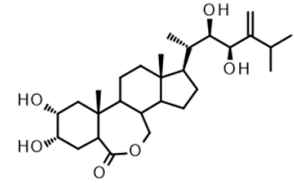

Dolicholide

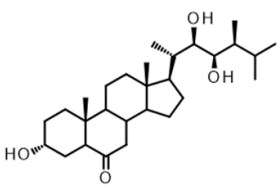

Typhasterol

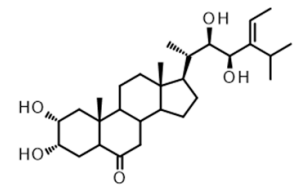

28-Homodolichosterone

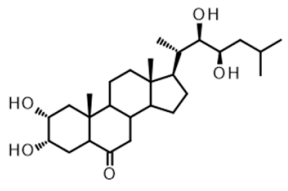

28-Norcastasterone

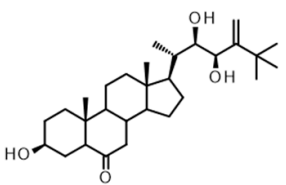

3-Epi-2-deoxy-25-methyldolichosterone

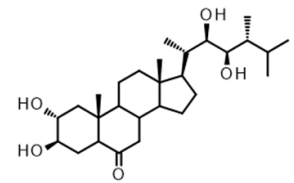

3,24-Diepicastasterone

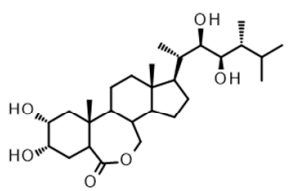

24-Epibrassinolide

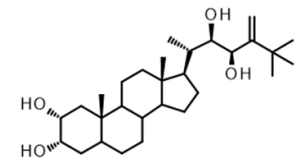

6-Deoxo-25-methyldolichosterone



Dolichosterone

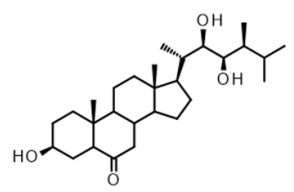

Teasterone

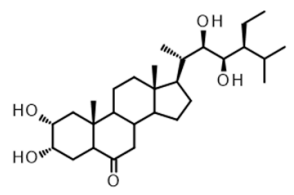

28-Homocastasterone

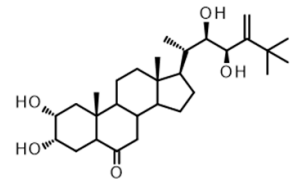

25-Methyldolichosterone

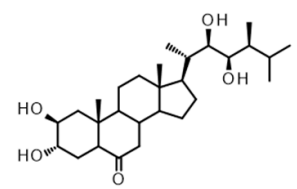

2-Epicastasterone

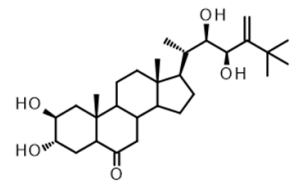

2-Epi-25-methyldolichosterone<smiles>CC(C)C(C)[C@H](O)[C@H](O)[C@H](C)[C@H]1CCC2C3CC(=O)C4C[C@@H](O)[C@@H](O)[C@H](O)C4(C)C3CC[C@]21C</smiles>

$1 \beta$-Hydroxycastasterone

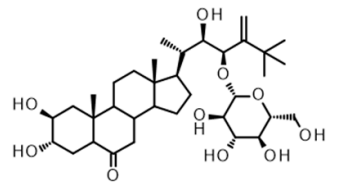

23-O- $\beta$-D-Glucopyranosyl-2-epi-25-methyldolichosterone

Figure 1. Cont. 


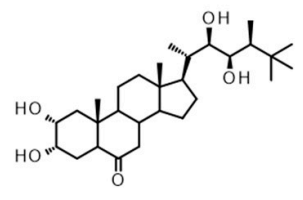

25-Methylcastasterone

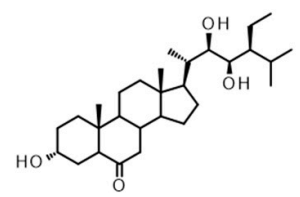

28-Homotyphasterol

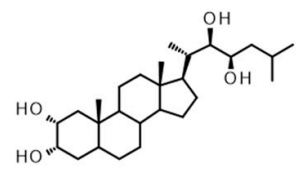

6-Deoxo-28-norcastasterone

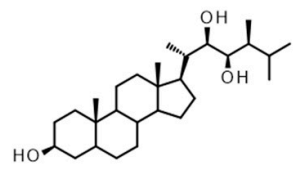

6-Deoxoteasterone

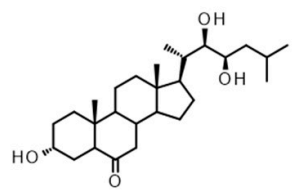

28-Nortyphasterol

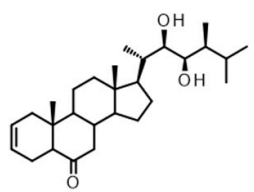

Secasterol

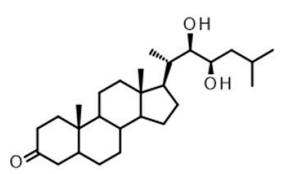

3-Dehydro-6-deoxo-28-norteasterone

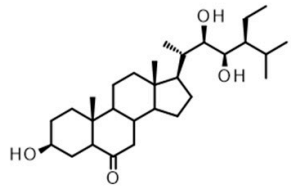

28-Homoteasterone

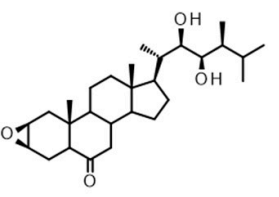

Secasterone

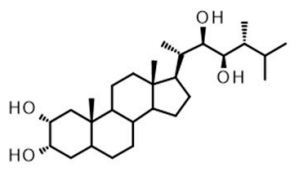

6-Deoxo-24-epicastasterone

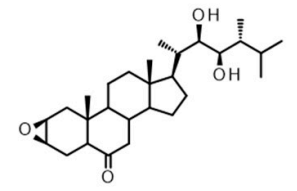

24-Episecasterone

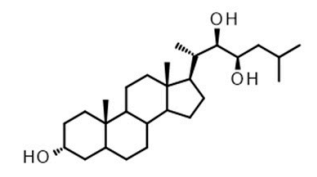

6-Deoxo-28-nortyphasterol<smiles>CC(C)C(C)C(=O)C(O)[C@H](C)C1CCC2C3COC(=O)C4C[C@@H](O)C(O)CC4(C)C3CCC21C</smiles>

Cryptolide<smiles>CC(C)C(C)C(O)C(O)[C@H](C)[C@H]1CCC2C3COC(=O)C4CC(O)CCC4(C)C3CCC21C</smiles>

3-Epi-2-deoxybrassinolide

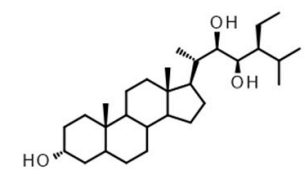

6-Deoxo-28-homotyphasterol

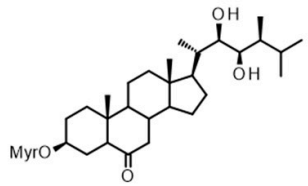

Teasterone-3-myristate<smiles>CC(C)C(C)[C@H](O)[C@H](O)[C@H](C)[C@H]1CCC2C3CCC4C[C@@H](O)CCC4(C)C3CCC21C</smiles>

6-Deoxotyphasterol<smiles>CC(C)C(C)[C@H](O)[C@H](O)[C@H](C)[C@H]1CCC2C3COC(=O)C4C[C@@H](O)CC[C@]4(C)C3CC[C@]21C</smiles>

2-Deoxybrassinolide

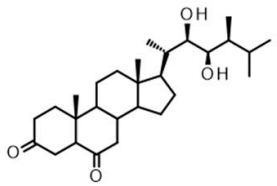

3-Dehydroteasterone

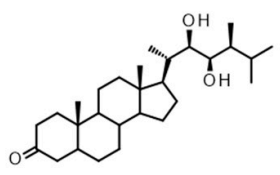

3-Dehydro-6-deoxoteasterone

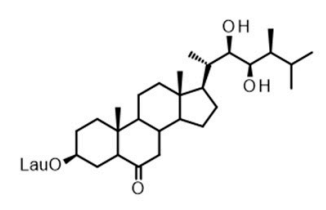

Teasterone-3-laurate

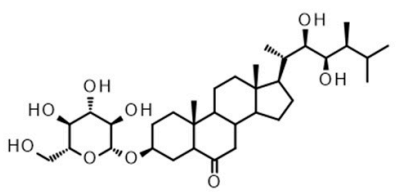

$6 \alpha$-Hydroxycastasterone

3-O- $\beta-D-$ Glucopyranosylteasterone

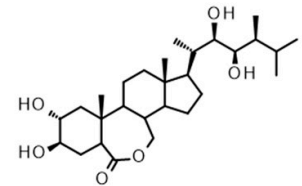

3-Epibrassinolide<smiles>CC(C)C(C)C(=O)C(O)[C@H](C)C1CCC2C3CC(=O)C4C[C@@H](O)C(O)CC4(C)C3CCC21C</smiles>

23-Dehydro-2-epicastasterone

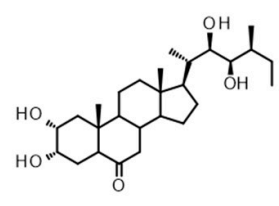

26-Norcastasterone

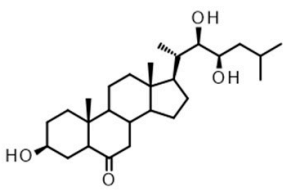

28-Norteasterone

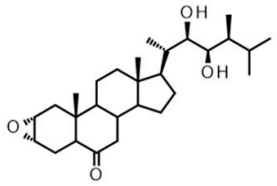

2,3-Diepisecasterone

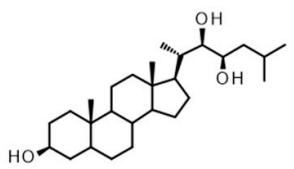

6-Deoxo-28-norteasterone

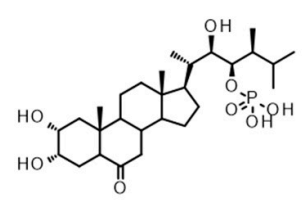

Castasterone 23-phosphate

Figure 1. Natural brassinosteroids isolated from or detected in plant sources. 


\section{Brassinosteroids: Functions and Signaling Pathway}

Due to BRs' growth regulator activity, this class of phytohormones is involved in a range of developmental processes, including cell division and elongation, vascular differentiation, reproductive development and the modulation of gene expression [51]. BR-deficient and -insensitive mutants in Arabidopsis thaliana (hereafter called Arabidopsis) present dwarfism, short petioles, delayed flowering, and reduction in fertility phenotypes. Equivalent mutants in other eudicot species such as tomato (Solanum lycopersicum), pea (Pisum sativum), and petunia (Petunia hybrida), as well as in monocots, like rice (Oryza sativa), barley (Hordeum vulgare), and maize (Zea mays) showed comparable phenotypes [52-54].

The main responsible for BR-mediated responses are BZR1 (BRASSINAZOLE RESISTANT 1) and BES1 (BRI1-EMS SUPPRESSOR 1), also named BZR2, the two major BR signaling pathway transcription factors, which regulate a range of genes involved in different physiological processes, such as developmental responses, protein metabolism, cellular transport and signaling, cell wall biosynthesis, chromatin and cytoskeleton components, environmental responses, and hormone responses [55].

\section{Signaling Pathway}

In previous years, a combination of genetic, biochemical and proteomic approaches have accelerated the understanding of the BR signaling pathway in Arabidopsis [52,56-58]. Upon BR binding, BRI1 (BRASSINOSTEROID INSENSITIVE 1), a plasmatic membrane leucine-rich repeat (LRR) receptor-like kinase (RLK) [59,60], which functions with its coreceptor BAK1 (BRI1-ASSOCIATED RECEPTOR KINASE 1) [61-63], generates a phosphorylation cascade [64,65]. Activation of the receptor and coreceptor stimulates the phosphorylation of BKI1, the inhibitor of BRI1 [66,67], leading to its dissociation from the plasma membrane and further association with 14-3-3 proteins. The 14-3-3 proteins are involved in the interaction and cytoplasmic retention of BZR1 and BES1 [68-72]. Concomitantly, activated BRI1 is also involved in the phosphorylation of the BSKs (BR-SIGNALING KINASE 1) and CDG1 (CONSTITUTIVE DIFFERENTIAL GROWTH 1), which both subsequently activate BSU1 phosphatase (BRI1 SUPPRESSOR 1) [57,73-75]. BSU1 is responsible for dephosphorylating BIN2 (BRASSINOSTEROID-INSENSITIVE 2), a GSK3-like kinase and the major repressor of the BR signaling pathway [72], which is posteriorly repressed by KIB1 (KINK SUPPRESSED IN BZR1-1D), an F-box ubiquitin ligase that does not allow the association of BIN2 with BZR1/BES1, culminating in its ubiquitination and degradation [76]. Upon BIN2 inactivation, BZR1 and BES1 are rapidly dephosphorylated by PP2A (PHOSPHATASE 2A) and subsequently dissociated from 14-3-3 proteins, causing them to accumulate into the nucleus, resulting in the regulation of many BR-responsive genes [77].

In the absence of BR, BKI1 binds to the intracellular domain of BRI1, preventing its association with its coreceptor BAK1 [66]. In turn, BIN2 is activated, and 14-3-3 proteins are associated with BZR1 and BES1, maintaining their dephosphorylated form and blocking their capability of shuttling to the nucleus for the regulation of thousands of BR responsive genes [67]. It is worth mentioning that previous studies have indicated that BR increases the expression of SBI1 (SUPPRESSOR OF BRI1), a positive regulator of BR1 degradation that methylates PP2A and controls its membrane-associated subcellular localization. As such, the relocation of methylated PP2A at membranes facilitates its association with the BR-activated BRI1, leading to BRI1 dephosphorylation and degradation, and, in turn, the termination of BR signaling. These data indicate that PP2A and SBI1 provide a negative feedback mechanism that triggers BRI1 turnover after activation of the BR signaling pathway [78]. The current model of the BR signaling pathway can be observed in Figure 2. 


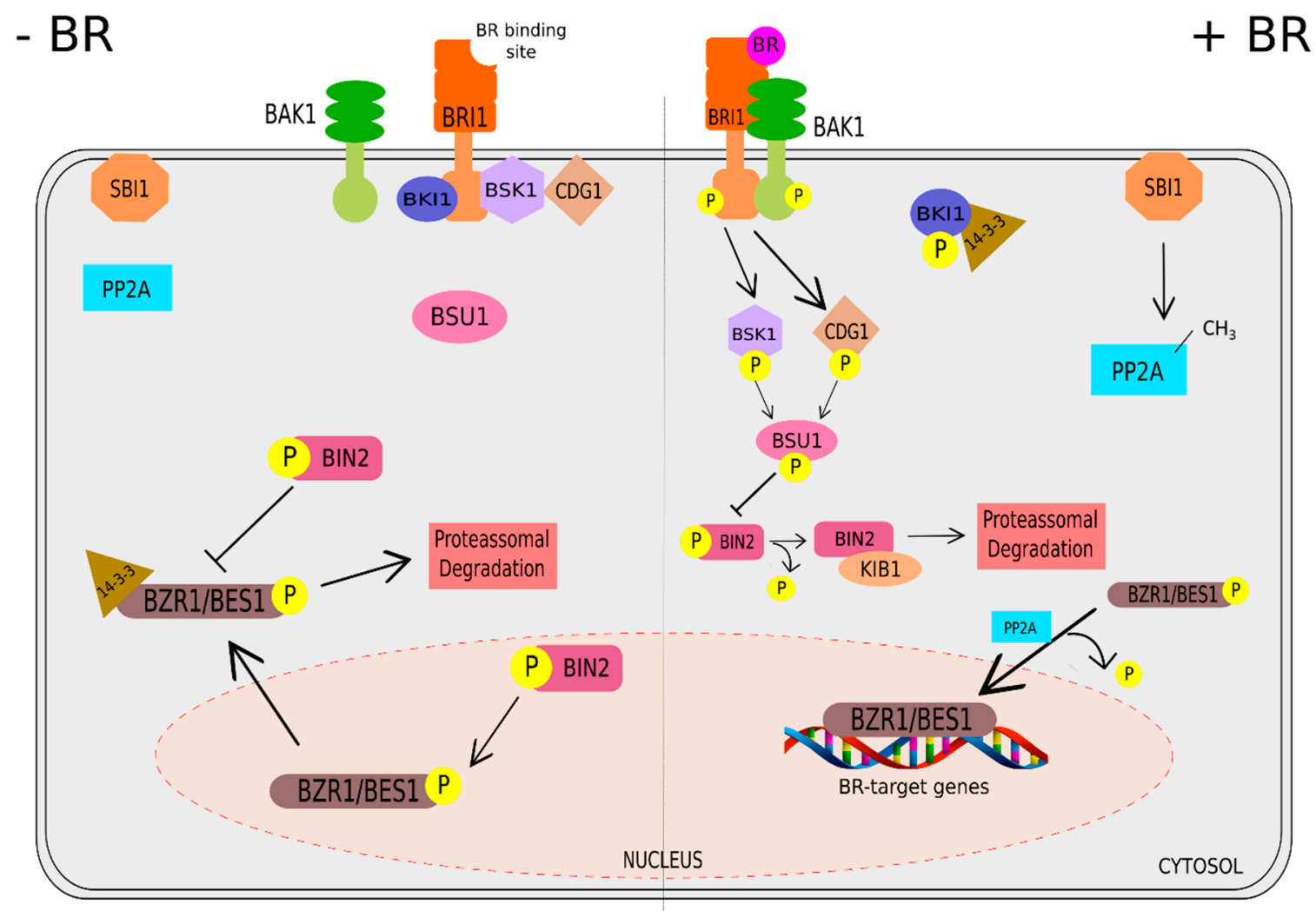

Figure 2. Current model of the signaling pathway in the presence or absence of brassinosteroids (BRs) in Arabidopsis. In the absence of BR, the receptor kinase BRI1 (BRASSINOSTEROID INSENSITIVE 1) does not heterodimerize with its coreceptor BAK1 (BRI1-ASSOCIATED RECEPTOR KINASE 1), maintaining their inactive forms. Consequently, BIN2 (BRASSINOSTEROID-INSENSITIVE 2), a negative regulator of BR signaling pathway, is free to constitutively phosphorylate BZR1 (BRASSINAZOLE RESISTANT 1) and BES1 (BRI1-EMS SUPPRESSOR 1), the two master transcription factors of BR-induced responses, inducing their interactions with 14-3-3 proteins that, in turn, promotes the cytoplasmic retention of BZR1/BES1, suppressing their DNA-binding activity. On the other hand, in the presence of BR, the activation of BRI1 triggers its autophosphorylation and partial kinase activity and dissociation from its inhibitor BKI1, which is attached at the BRI1 kinase domain. This leads to its heterodimerization with BAK1, and transphosphorylation to complete BRI1 kinase activity. Activated BRI1 then phosphorylates BSKs (BR-SIGNALING KINASES) and CDG1 (CONSTITUTIVE DIFFERENTIAL GROWTH 1) which both phosphorylate BSU1 (BRI1 SUPPRESSOR 1), leading to BIN2 dephosphorylation. BIN2 is subsequently restrained by KIB1 (KINK SUPPRESSED IN BZR1-1D), which prevents the association of BIN2 with BZR1/BES1 and facilitates its ubiquitination and degradation. The inactivated form of BIN2 allows BZR1 and BES1 to enter into the nucleus and regulate the expression of BR target genes. Additionally, PP2A (PHOSPHATASE 2A) also positive regulates BR signaling by dephosphorylating BZR1 and BES1, whereas SBI1 (SUPPRESSOR OF BRI1) deactivates BRI1 through the methylation of PP2A.

\section{Cross-talk between BRs and Other Phytohormones in Plant Growth, Development, and Stress Responses}

\subsection{Brassinosteroids and Auxins}

The events along the plant life cycle rely on coordinated changes at the molecular level in plant growth in a complex network, requiring a synchronism involving different hormone signals. Over the years, BR and auxin have been considered as two important phytohormones that function as master regulators in different plant development processes such as root development and stem elongation $[79,80]$. 
The interaction between BR and auxin has been observed in different processes. Hypocotyl elongation assays showed that auxin-responsive mutants display reduced BR sensitivity [81]. Similarly, BR treatment significantly enhanced auxin response in hypocotyl elongation, indicating that the auxin response depends on the presence of a functional BR signal transduction pathway [82].

Similar to BR, auxin is a growth-promoting hormone that is synthesized mostly in the shoot apical meristem (SAM), young leaves and in the root along the meristem $[83,84]$ that binds to the TRANSPORT INHIBITOR RESPONSE1/AUXIN SIGNALING F-BOX (TIR1/AFB) receptor protein, which triggers the degradation of the AUXIN/INDOLE ACETIC ACID (AUX/IAA) transcriptional repressor protein. Upon ubiquitylation and subsequent degradation of the Aux/IAA proteins, AUXIN RESPONSE FACTOR (ARF), a family of transcription factors, including 25 and 23 members in rice and Arabidopsis, respectively, are released to activate gene expression through the recognition of auxin-responsive DNA Elements (AuxREs) [85-87]. The balance between AUX/IAA and ARF is a key control point in auxin signaling and orchestrates the molecular mechanisms by which auxin-BR impacts plant growth and development [88]. Besides, dual roles have been reported for ARFs: transcriptional activation and repression of gene expression.

The first molecular evidence of transcriptional regulation of ARF genes by BR came from the downregulation of ARF4 and ARF8 in BL-treated hypocotyls of Arabidopsis wild-type (WT) seedlings, contrasting the high level of expression observed in BR-deficient mutants [89]. In another study, the overexpression of ARF8 in Arabidopsis inhibited the hypocotyl growth and resulted in a weaker apical dominance [90]. These results indicate that ARF8 negatively regulates the auxin response in shoot elongation. The transcriptional activation activity of $A R F$ was observed by chromatin immunoprecipitation-sequencing (ChiP-seq) and transgenic analyses where the interaction between BZR1 and ARF6 enhanced their DNA-binding activity capacity and promoted the activation of shared-target genes involved in hypocotyl elongation [91,92]. In addition, the ChIP assay confirmed that BZR1 binds to IAA19 and ARF7 promoters to potentiate the auxin response [93]. Interestingly, the application of high concentrations of BL or the hypersensitive bzr1-1D mutant resulted in curved and shorter hypocotyls [94]. All of these results indicate that BZR1 and an appropriate BR concentration are required for the auxin promotion of hypocotyl elongation in Arabidopsis seedlings grown in the dark. On the other hand, at low BR levels, another component of the BR signaling pathway, BIN2, phosphorylates ARF7 and ARF19, enhancing their DNA-binding capacity during lateral root development [95]. This corroborates with the inhibition of root growth by high levels of BR [96]. Nevertheless, the BIN2-mediated phosphorylation of ARF2 in the gain-of-function bin2 mutant was shown to reduce ARF2 DNA-binding and its repressing activity on shoot and root growth [82]. These results are a clear indication that the auxin-BR response involves a dynamic coordination of both transcriptional and post-transcriptional regulation of ARFs via BZR1 and BIN2 to control plant growth and development in a spatiotemporal context.

Root development is determined by the balance between cell division and differentiation in the root meristem. Despite the well-known synergistic interaction in various developmental processes, in the case of root tips, BR and auxin interact antagonistically in controlling gene expression, stem cell maintenance and cell elongation. Additionally, a finely balanced concentration between these hormones is required for optimal root growth [97]. BR affects root growth in a concentration-dependent manner to control the root meristem size. The short root phenotype of the BR-insensitive bri1-116 mutant is suppressed by low concentrations of BL [98]. Additionally, specific cell types of the root meristem are affected by different levels of BR. Chaiwanon et al. (2015) [97] observed that the expression of bzr1-1D in the bri1-116 mutant epidermis cells increased the elongation zone of the root meristem. On the other hand, high levels of BR/BZR1 in the endodermis or in the quiescence center (QC) had no effect on the bri1-116 phenotype, indicating the requirement of different concentrations of BR/BZR1 for the normal function of root cells [97]. Collectively, these observations support a model whereby, under different levels of BR, BZR1 contributes to the gene expression pattern by targeting different 
genes in distinct cells, as is the case in the induction of genes expressed in the transition-elongation zone, but repressing genes in the QC and surrounding stem cells [97].

BES1 is another transcription factor of the BR signaling pathway and shares $88 \%$ sequence identity with its closest paralog, BZR1. BES1 also tightly connects the BR pathway to other hormone responses in Arabidopsis. In the gain-of-function bes1-1D, a dominant mutation that leads to overaccumulation of BES1, some auxin-responsive genes are induced [99]. The auxin-responsive gene SAUR15 is upregulated in the bes1-1D mutant and induced by BR without increasing the endogenous auxin levels [100]. Interestingly, the auxin efflux carriers PIN4 and PIN7, which maintain the distribution and endogenous auxin gradient, are controlled by BES1 [101]. When grown in the dark, the phenotype of the bes1-1D mutant was shown to be similar to bzr1-1D [77]. However, both mutants have distinct light-grown phenotypes that are consistent with their effects on the feedback regulation of BR biosynthetic genes [99]. While the bzr1-1D mutant has reduced BR levels and lower expression of the BR biosynthetic pathway gene CONSTITUTIVE PHOTOMORPHISM AND DWARFISM (CPD), bes1-1D has only a small effect on CPD gene expression [99]. This suggests that BZR1 plays a major role in the activation of the BR negative feedback pathway that inhibits BR biosynthetic genes [77]. Interestingly, another BR biosynthetic gene, BREVIS RADIX (BRX), is under a feedback loop during Arabidopsis root development and mediates feedback between auxin and BR signaling [102]. In the future, it would be interesting to evaluate the effects of BZR1 on BRX gene expression in different root tissues at different BR levels.

From the molecular point of view, the question that needs to be addressed is: what is the conversion point of different hormone signals at different stages of development, at different organs and under different hormone levels? Unfortunately, there is no clear answer yet. Studies on the relationship between BR and auxin might clarify the complex biological significance of the question above.

In summary, Figure 3 shows a schematic working model for the cross-talk between BR and auxin. The concept behind this model is a mechanism involving the control of BR-auxin interaction by a tissue-specific transcriptional/post-transcriptional regulation circuit in a hormone dose-dependent manner. A detailed molecular link between the interaction of BR and auxin in plant growth remains elusive, and further investigations will be essential to understand the spatiotemporal pattern of BR-auxin cross-talk.

\subsection{Brassinosteroids and Gibberellins}

\subsubsection{BR-GA Cross-talk: The Signaling Model}

A long-standing theme in plant development is how, when and where hormonal cross-talk orchestrates a myriad of developmental cues while simultaneously transmitting environmental inputs. Over the years, this multidynamic mapping of hormonal signaling has elegantly been deciphered by transcriptional and post-transcriptional regulatory mechanism models. Therefore, it is not surprising that there has been a strong effort over the last two decades, particularly in the last six years, to develop an improved integrated model of BR-GA coordination. To date, three out of eight classes of hormones in plants have been identified as major classes of growth-promoting hormones which include auxins, gibberellins, and brassinosteroids. Despite their interdependences in playing a wide range of growth and developmental processes in different contexts throughout the life cycle of plants, they also act through a woven network, regulating themselves and several downstream effects [103].

Gibberellins are a group of tetracyclic diterpenoids, synthesized by a multistep process, which act as mobile signals [104] with diverse intermediates being processed into different cellular compartments [105]. Several studies have shown the complex spatiotemporal regulation of their biosynthesis in different tissues, cell types and developmental phases [106]. GAs' distribution and mobility, recently clarified through the report of two GA transporters (i.e.; the nitrate transporter 1/peptide transporter family (NPF) [107] and SWEET13/14 proteins [108]) have long been described to long-distance movement, but their combinatorial effects on GA activity at a cellular resolution have 
only recently been clarified through novel approaches using the GA biosensor (termed GPS1) [109] and a fluorescently labeled version of active $\mathrm{GA}_{3}$ and $\mathrm{GA}_{4}$ (termed GA-FI) [110]. In contrast to this multifaceted regulation, their signal transduction mechanism seems to be relatively straightforward, whereas GA-induced DELLA degradation acts as a central regulatory switch for GA signaling (Figure 4). Briefly, active GAs are recognized and bound to their receptor GIBBERELLIN INSENSITIVE DWARF1 (GID1), which, in turn, binds to the N-terminal of DELLA proteins, relieving their repression by promoting their degradation via the ubiquitin-proteasome pathway [111]. Of note, the existence of a DELLA-independent signaling pathway has also been reported through the increase of $\left[\mathrm{Ca}^{2+}\right]_{\mathrm{cyt}}$ within a few minutes after GA treatment [112].
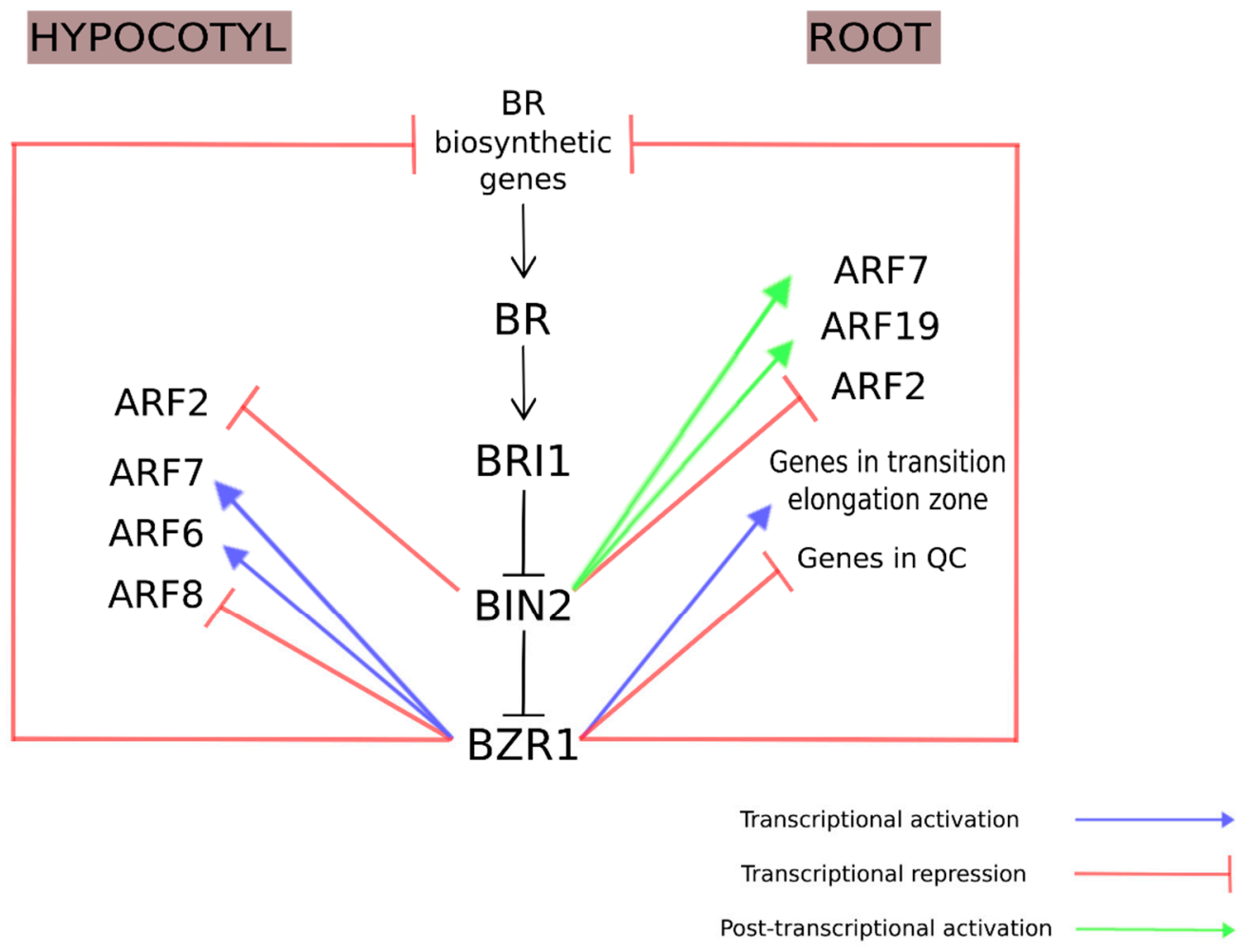

Figure 3. Schematic working model of regulatory interactions between BR and auxin in root and hypocotyl growth. The green arrows represent the post-transcriptional activation of AUXIN RESPONSE FACTOR (ARF) by BRASSINOSTEROID-INSENSITIVE 2 (BIN2). The blue arrows represent the transcriptional activation of ARF and auxin-responsive genes in the root transition elongation zone by BRASSINAZOLE RESISTANT 1 (BZR1). The red arrows represent the transcriptional repression of ARF and auxin-responsive genes in the root quiescence center (QC) by BZR1. The negative feedback of biosynthetic genes coordinated by BZR1 in both root and hypocotyl elongation is also represented by red arrows.

The most convincing evidence of this tangled interaction between BR and GA came in the late 1990s, with the discovery of the remarkably resembled phenotypes (being de-etiolated in the dark and dwarf stature in the light) between GA- and BR-deficient Arabidopsis mutants [96,113-117]. Subsequently, several detailed physiological, metabolic and genetic studies in pea (Pisum sativum) [118], mung bean (Vigna radiate) [35], cucumber (Cucumis sativus) [119], rice (Oryza sativa L.) [120], and, in particular, in Arabidopsis [121], started to reveal evidence of a cooperative and interdependent relationship between BRs and GAs, but with multiple layers of this complex interaction acting in a species-, tissue-, and dose-dependent manner. The elusive nature of such responses in this complex interplay was clarified further when, in 2012, a direct physical cross-talk between their signaling pathways was revealed, and the signaling model was proposed (Figure 4). In fact, DELLA not only interacts with BZR1/BES1, but also exerts an inhibitory effect on BZR1 transcriptional activity [122-124]. 
This mechanistic molecular framework became the stepping stone towards expand the understanding of the integration between BR-GA activities, whereas if DELLAs inhibit BZR1 activity and GA-induce DELLA degradation, GA and BR should affect the expression of BZR1 target genes similarly in the control of plant growth and development.

Consequently, this strengthened notion was further examined and validated through the coregulation of common target genes mediated by the BZR1-DELLA interaction. Bai and coworkers elegantly firstly demonstrated that 419 (35\%) out of 1,194 genes differentially expressed in ga1-3 (GA-biosynthesis deficient) compared to WT plants, were also affected in the bri1-116 (BR-insensitive) mutant, of which 387 (92.3\%) of the coregulated genes were affected in the same way by these mutants. Secondly, they analyzed RNA-sequencing data from GA-treated WT and GA-treated WT grown on PPZ (a specific inhibitor of BR biosynthesis) medium, identifying 3,570 and 1,629 differentially regulated genes, respectively. Again, this striking data suggested that around $66.7 \%$ of GA-regulated genes require BR, emphasizing the important role of BR in the GA regulation of genome expression [122]. Consistent with these data, other groups showed that hypocotyl elongation promoted by GA was eliminated in Arabidopsis seedlings with reduced BR biosynthesis (i.e.; de-etiolated-2 (det2) mutants or brassinazole (BRZ) treatment), indicating that cell elongation largely relies on the appropriate action of both hormones $[123,125]$. Later experiments, discussed in more detail below, showed that the capacity of GA to rescue the growth defects of BR mutants is dependent on the developmental stage, on the physiological conditions and also on the fact that the GA pathway is only one of the branched pathways of BR-regulated growth [126].

Even in the absence of BR, GAs might also regulate BZR1-dependent gene expression, at least in part, since GA treatment slightly increases the dephosphorylation state of BZR1, its active form, likely through phosphatase PP2A proteins [124]. This action might explain the increased BZR1-DNA binding in vivo and GA-induced the modulation of BR transcriptional outputs [122]. Interestingly, this slight rise in the dephosphorylated BZR1 concentration was abolished in the presence of the protein phosphatase inhibitor okadaic acid (OA), and, in the same manner, in paclobutrazol-treated plants, which also showed a reduced level of two PP2AB' subunits (PP2AB' $\alpha$ and PP2AB' $\beta$ ) [124]. In future studies, it will be exciting to elucidate how GA and DELLA act on PP2A regulation to promote the phosphorylation state of BZR1. The fact that DELLA proteins interact exclusively with the dephosphorylated BZR1 indicates that BR signaling enhances GA signaling by promoting the BZR1-DELLA interaction and, therefore, the alleviation of DELLA's restraint imposed on GA-mediated growth [124]. This BZR1 titration might explain why, surprisingly, BR was shown to strongly increase the abundance of the DELLA protein at the early elongation stages postgermination in Arabidopsis [125]. However, on the other hand, another group showed that neither BR treatment, nor BR biosynthesis or signaling mutants affected the accumulation of DELLA proteins in seedlings of 12-day-old Arabidopsis plants [124]. One explanation for these seemingly contradictory findings might be related to the developmental stage and tissue studied, evidencing the complexity of this hormonal interaction.

\subsubsection{The Expanded and Integrated Model}

Although this attractive signaling model could shed some light on the BR-GA interaction, recent detailed results on the potential interaction between BR and GA biosynthesis brought an informative readout at the level of hormonal biosynthesis, providing a novel expanded and integrated model of BR-GA cross-talk. Nonetheless, it is worth mentioning that a previous study had already demonstrated that BR promotes the expression of GA biosynthetic genes, and that DELLA can also modulate negative feedback in the BR biosynthetic genes by preventing the DNA-binding ability of BES1 and BZR1 proteins [125]. This overlooked biosynthetic cross-talk gained some attention following the recent demonstration by independent groups that the active GA contents (and various GA intermediates therein for Arabidopsis) were reduced in Arabidopsis (ASKO-oe) and rice (d11, GSK2oe, and dltt) BR deficient mutants in comparison to those in WT plants. Similarly, an increase in the $\mathrm{GA}_{1}$ level in BR-accumulating rice (Do and $m 107$ ) lines was observed [126,127]. Strengthening these findings, and 
also in line with previous results, the expression levels of two genes (GA20ox and GA3ox) encoding key enzymes in the rate-limiting step of GA production were shown to be impaired in BR mutants, but were also strongly increased after BR treatment in Arabidopsis and rice plants, clearly indicating that BR influences GA biosynthesis in dicot and monocot plants. Such findings became more evident through the use of bioinformatics, ChIP, and in vitro DNA binding studies, which demonstrated that BZR1/BES1 can directly bind to the target promoters of GA20ox, GA3ox, and GA2ox from Arabidopsis and rice plants. These analyses revealed that BZR1/BES1 binding cis-elements are highly enriched on these promoters, including the BR-response element (BRRE, CGTG ${ }^{\mathrm{T}} / \mathrm{C}_{\mathrm{G}}$ ), G-box (CACGTG) and a type of E-box (CATGTG) in rice, and a non-E-box $\left(\mathrm{AA}^{\mathrm{T}} /{ }_{\mathrm{A}} \mathrm{CAAnnnC} / \mathrm{C} / \mathrm{T}\right)$ motif in Arabidopsis [126,127]. Importantly, there was a higher enrichment of BES1 on these promoters followed by BR treatment, evidencing that the dephosphorylation of BZR1/BES1 increases GA production.

Extending the analysis to the effects of GA20ox expression on BR mutant phenotypes, complementation of the bri1-301 mutant with GA20ox1 under the control of the BRI1 promoter restored various growth defects of the BR-deficient seedlings, demonstrating that some defects are related to GA deficiency [126]. Additionally, in contrast with the previous observations that BR- deficient and -insensitive mutants conferred insensitivity to GA, two independent groups demonstrated that externally applied GA could restore growth defects of Arabidopsis and rice BR mutants [126,127]. However, the developmental stage, environmental context, tissue specificities, hormone concentration, and species must be considered during the study of this positive loop between GA and BR.

At this stage, the proposed model postulates that BR activates BZR1/BES1 post-translationally to induce GA biosynthesis, and the increased GA induces DELLA degradation to further release BZR1/BES1 activity (Figure 4). Although this expanded model has incited a debate around the relative importance of the biosynthesis and signaling pathways [128-130], it is essential to highlight the applicability of this model to different contexts, as described above. Nevertheless, recent mathematical modeling and analysis of BR-GA cross-talk revealed that the signaling model (BZR1/BES1-DELLA interaction) exerts a stronger influence on the dynamics of the BR and GA signaling pathways than the BZR1/BES1-mediated biosynthesis of GA. Besides, the stability of this feed-forward model is mainly dependent on the mechanisms involved in the phosphorylation state of BZR1/BES1 proteins and the cellular localization of these processes [131].

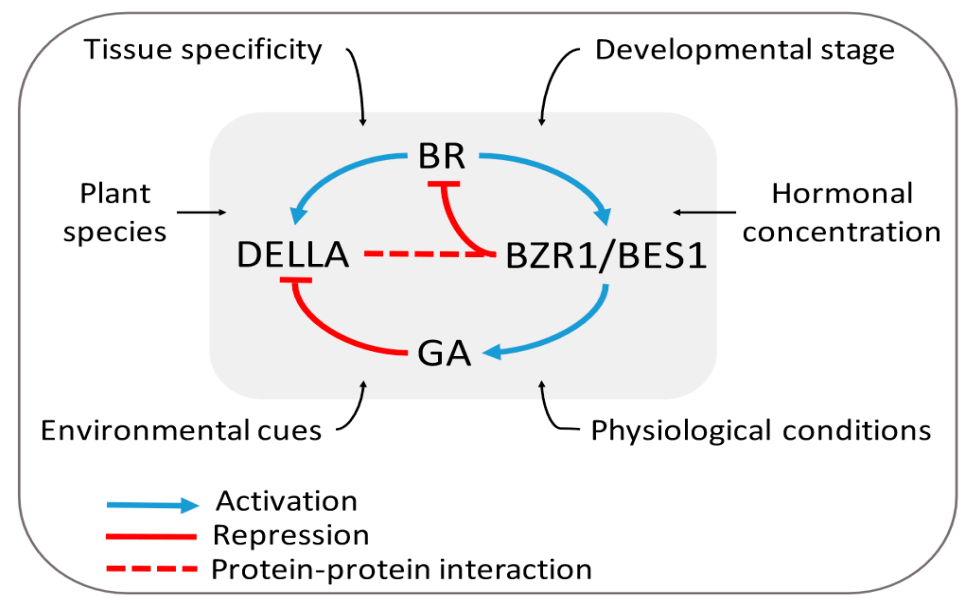

Figure 4. The integrated model for BR-Gibberellin (GA) cross-talk. BR activates BRASSINAZOLE RESISTANT 1/BRI1-EMS SUPPRESSOR 1 (BZR1/BES1) to promote GA biosynthesis and production. As a consequence, GAs degrade DELLA proteins, releasing their repressive action on BZR1/BES1 activity. Some critical factors, emphasized above, may influence and alter this interaction over time and should be considered when discussing BR-GA coordination in plants (e.g.; BR-induced accumulation of DELLA at dawn in the early stages of Arabidopsis development). 


\subsubsection{Is the BR-GA Antagonism an Alternate Strategy to Tackle Biotic and Abiotic Stresses?}

As pointed out above (Figure 4), the high degree of complexity in BR-GA cross-talk can be attributed to several factors that profoundly influence BR and GA homeostasis. One interesting example is the fact that plant pathogens may exploit endogenous hormones or produce deceptive BR or GA (or mimics thereof) signals for their own advantages in order to manipulate and subdue their host's immunity. In rice, the root pathogen Pythium graminicola uses endogenous BR as a virulence factor and manipulates the host BR signaling to alleviate effective GA-mediated defenses. In this case, BR suppresses GA biosynthesis and induced GA repressor genes (GA20x3) that indirectly stabilize the rice DELLA protein, SLENDER RICE 1 (SLR1) [132]. Thus, as a virulence strategy, BR promotes susceptibility to this particular pathogen, disarming the plant's defense signaling circuitry, which is in contrast to the protective effects of BRs that have been unveiled so far against myriad fungal, viral, and bacterial pathogens.

Intriguingly, the same BR-GA antagonism mechanism was reported in the submergence response in rice [133]. The tolerant M202-Sub1 line adopts a quiescent strategy that limits shoot elongation during transient flooding, conserving energy until floodwaters retreat. The increased BR level in these plants during submergence induces a GA catabolic gene (GA2ox7) and the DELLA protein SLR1, restricting growth through the repression of GA signaling. In keeping with this data, BR pretreatment of the intolerant M202 line before inundation was shown to restrict shoot elongation, conferring submergence tolerance [133].

In contrast to the antagonistic control of BR on GA metabolism, the positive effect of BR on DELLA protein stability may offer a mechanistic explanation for the abiotic stress tolerance conferred by BR. The positive correlation between DELLA protein levels and tolerance to abiotic stresses has been attributed to elevated expression of reactive oxygen species (ROS)-scavenging enzymes [134]. However, the dynamics and stability of DELLA and BZR1 protein complexes in response to pathogen and abiotic stresses remain elusive.

In summary, the intricate interconnection of BR with GA illustrates the functional versatility of these hormones whereby the integration of their outputs and signals of adverse conditions stimulates a balance between plant defense and growth responses. Nonetheless, the understanding of how the BR-GA interplay acts in biotic and abiotic stresses is still far behind that of the classic defensive hormones JA, ET, and SA.

\subsection{Brassinosteroids and Cytokinins}

Cytokinins are a group of phytohormones that play important roles in several biological processes, such as the development of aerial and subterranean organs, light responses, mineral enrichment, and responses to abiotic stresses [135-137]. The key enzymes involved in CK metabolism are isopentenyltransferases (IPTs), which are responsible for the biosynthesis of bioactive CKs, and CK oxidases/dehydrogenases (CKXs), which are responsible for the inactivation of bioactive CKs [135], both targets of BR-mediated responses.

The main interplay between CKs and BRs seems to be related to plant growth regulation [138]. The CKX3 gene from Arabidopsis directs the breakdown of CKs, and when overexpressed under the control of a root-specific promoter PYK10, lower CKs levels in roots were observed, causing a reduction of root growth and also a weak reduction of leaf growth in Arabidopsis [136]. On the other hand, plants ectopically expressing both $C K X 3$ and BRI1 present a synergistic increase in leaf and root growth. In agreement, PYK10::CXK3 transgenic plants treated with exogenous BR showed an accentuated growth of lateral roots compared to WT plants, strongly suggesting a cross-talk between BRs and CKs that controls growth and developmental processes [138].

Moreover, the interplay between BR and CK can be observed in CK-induced anthocyanin production [139]. Arabidopsis mutant seedlings defective in BR biosynthesis (dwf4, dwf4-102, and psc1) and BR signaling (bri1-4), were submitted to different trials to evaluate the effects of BR on CK-induced anthocyanin accumulation. The $d w f 4$ and bri1-4 plants presented reduced CK-induced 
accumulation of anthocyanin, but when WT plants were treated with exogenous BR, an increase in anthocyanin levels was observed. Similarly, CK-induced expression of anthocyanin biosynthetic genes, such as dihydroflavonol reductase, leucoanthocyanidin dioxygenase, and UDP-glucose:flavonoid-3-O-glucosyl transferase, presented an accentuated reduction in the dwf4-102 and bri1-4 lines compared to WT. In addition, WT plants treated with CK presented higher expression of transcription factors related to anthocyanin production, including anthocyanin pigment 1 (PAP1), glabra 3 (GL3), and enhancer of glabra 3 (EGL3), but the same was not observed in the bri1-4 and dwff-102 lines. These data provide evidence that BR may boost CK-induced anthocyanin biosynthesis by positively mediating the expression of biosynthesis and signaling genes as well as transcription factors involved in both cases [139].

As with various phytohormones, later evidence suggested that CKs play important roles in several abiotic stress responses [140-142]. Studies of the gain- and loss-of-function of selected genes suggested that CKs negatively regulate several stress responses. Constitutive overexpression of $C K X$ genes was implicated in CK deficiency and an increase in drought and salt tolerance, while the loss-of-function of IPT genes also led to increased stress tolerance due to decreasing bioactive CK levels [137]. Parallel experiments showed that the negative relation between the CK content and stress tolerance might be associated with a mutual interplay between CKs and ABA [143]. The treatment of CKX overexpressing lines and IPT silencing lines with exogenous ABA similarly resulted in the decrease of biologically active CK contents. Nevertheless, CK-deficient mutants were shown to be more sensitive to ABA compared to WT plants, leading to a higher induction of ABA-signaling marker genes under stress conditions (e.g.; AIL1, COR47, RAB18, RD29B, and SAG29) and subsequently, enhancing stress tolerance. These data suggest that the elevated stress tolerance in CK-deficient plants compared to WT plants may be related to the ability of these mutant plants to react more quickly to ABA and stressful conditions by further repression of the CK signaling pathway.

Besides the interplay of ABA and CK in stress tolerance regulation, other studies in rice (Oryza sativa) showed that BR might be associated with CK-mediated responses to drought stress in a different way. Rice transgenic lines expressing the IPT gene driven by a stress- and maturation-induced promoter $\left(P_{S A R K}\right)$ presented an increase in $C K$ content before the beginning of senescence as well as the upregulation of several genes involved in the activation of BR signaling (BRL3, BRI1, BH1, BIM1, and SERK1) and biosynthesis (DWF5 and HYD1), in water-stressed and well-watered plants. Under stress conditions, this resulted in a delay in stress symptoms such as leaf rolling, senescence, and decreased photosynthesis activity, which contributed to an increased grain yield [144].

It is well documented that CKs have an important role in the source/sink relationship [145]. During the vegetative and premature reproductive stages of cereal plants, the assimilated carbon is temporarily stocked in the stem and leaf sheaths in carbohydrate form. In the later stages of plant development, these stored compounds are subsequently remobilized to reproductive sink tissue as flowers and grain filling [146]. However, the maintenance of source/sink homeostasis is a major challenge during stress conditions, causing yield losses. In $P_{S A P K}:: I P T$ lines, the increase of $\mathrm{CK}$ content enabled the maintenance of source strength during drought stress, keeping higher yields compared to WT plants. It is also known that the application of BR is a powerful biotechnological tool to enhance crop yield [147-152]. According to the presented scenario, the changes in hormonal profile, including the upregulation of BR-related genes, can modify the source/sink relationship, providing a strong sink capacity to $P_{S A P K}: I P T$ line plants during water stress. Together, these data suggest that BR-CK cross-talk may contribute to the modification of source/sink relations, improving crop yield and stress responses.

It has been observed that $\mathrm{BR}$ and $\mathrm{ABA}$ present antagonistic actions [153]. BR-mediated signaling is regulated by ABA through the upregulation of BIN2 and downregulation of genes from the PP2C family, causing decreased activity of the BR signaling pathway [153]. The relative expression of three members of the PP2C family ( $P P 2 C 7, P P 2 C 6$, and PP2C53) was increased in WT plants under water stress. However, the expression of BIN2 was upregulated in plants of $P_{S A P K}:: I P T$ lines [153]. ABA is responsible for inhibiting BR effects during stress conditions. Therefore, the observed hormonal profile 
in the mentioned study and its consequences may be due to the interplay not only between CK and $\mathrm{BR}$, but also between the three hormones- $\mathrm{CK}, \mathrm{ABA}$, and $\mathrm{BR}$-in a complex manner that remains unclear [144]. The role of ABA in abiotic stress and its cross-talk with BR are discussed in more detail in Section 3.5. A suggested interplay between BR, CK, and ABA is represented in Figure 5.

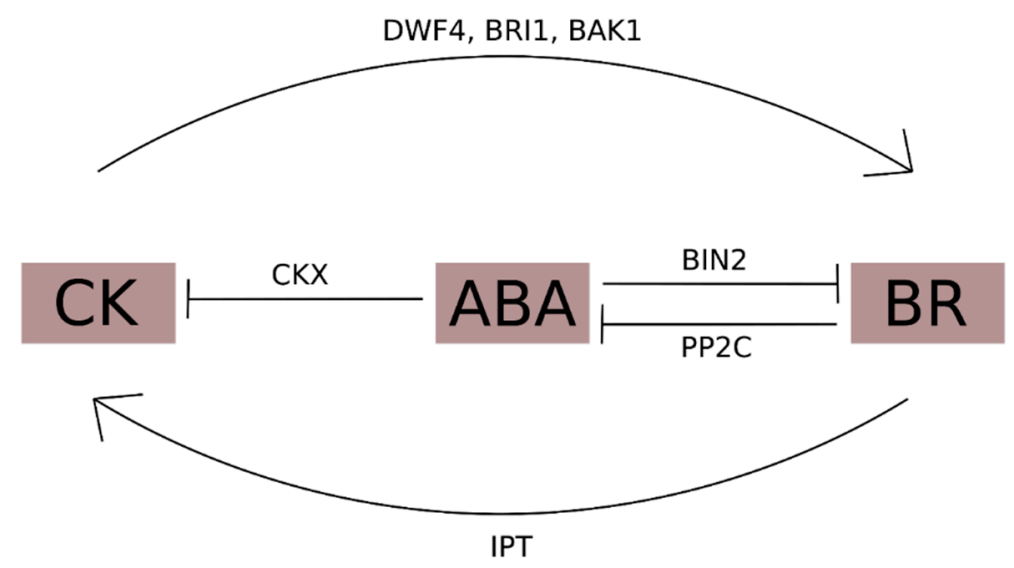

Figure 5. A putative interplay between brassinosteroid (BR), cytokinin (CK), and abscisic acid (ABA). ABA is responsible for inhibiting BR effects during stress conditions by upregulating BIN2 (BRASSINOSTEROID-INSENSITIVE 2), a major negative regulator of BR signaling, whereas $\mathrm{BR}$ is responsible for inhibiting ABA effects during growth processes through PP2C (PROTEIN PHOSPHATASE 2C), a major negative regulator of Snark proteins (positive regulators of ABA signaling). $\mathrm{ABA}$ is also responsible for inhibiting $\mathrm{CK}$ signaling by upregulating $C K X$ (CK oxidases/dehydrogenases), which play a major role in inactivating bioactive CKs. Despite ABA's role, BR and CK present positive interactions. While CK upregulates BR biosynthetic (DFW4) and signaling (BRI1, BAK1) genes, BR upregulates IPT (isopentenyltransferases), which are major enzymes responsible for the biosynthesis of bioactive CKs.

\subsection{Brassinosteroids and Ethylene}

Ethylene is a gaseous phytohormone with a simple structure. Because volatile substances move rapidly, they can act as regulators and coordinators of several growth and development processes, both in the tissue and in the whole organism, as well as facilitating plant-to-plant communication. Although the main function attributed to ethylene is fruit ripening promotion, other physiological processes, such as seed germination, senescence, and responses to abiotic and biotic stress factors, are also regulated by this hormone [154]. Ethylene biosynthesis requires the participation of five major components: the amino acid methionine which is converted into S-adenosyl methionine $\left(\mathrm{SAM}^{2}\right)$ and subsequently modified by the ACC-synthase enzyme (ACS) to form 1-aminocyclopropane-1-carboxylic acid (ACC), the direct precursor of ethylene. In turn, ACC is converted by the enzyme ACC-oxidase (ACO) into ethylene, a stable compound that can be transported throughout the plant [155].

Brassinosteroids influence ethylene biosynthesis mainly by regulating $A C S$ and $A C O$ activities [156]. The cross-talk between these two phytohormones presents two scenarios, with BR regulating ethylene production at the transcriptional and post-transcriptional levels. Regarding protein regulation, previous studies in Arabidopsis indicated that seedlings treated with exogenous BR show elevated levels of ethylene biosynthesis, at least partly through an increase in ACS5 protein stability by elevating its half-life [156]. Additionally, other studies have already found that BR may also regulate ethylene biosynthesis through the induction of ACS5 gene expression in Arabidopsis [157].

The regulation of ethylene biosynthesis by BR happens in a dose-dependent manner, where BRs can be positive as well as negative regulators, depending on the exogenous application dose (Figure 6) [158]. High levels of BRs stimulate ethylene biosynthesis by enhancing the stability of the ACS protein by preventing its degradation by the $26 \mathrm{~S}$ proteasome. On the other hand, low levels of BRs repress ethylene biosynthesis by increasing the activity of BZR1/BES1, the two major BR 
signaling pathway transcription factors that inhibit the transcription of ACS genes [158]. Experiments with banana fruit (Musa acuminata L.) showed that BZR proteins bind specifically to BRRE elements (CGTGT/CG) of at least one ACS gene (MaACS1) and two ACO genes (MaACO13 and MaACO14) in this species. An expression analysis showed that the expression of MaBZR1, MaBZR2, and MaBZR3 decreases continuously during fruit ripening. Moreover, MaBZR1 and MaBZR2 are capable of suppressing the transcription of these three ethylene biosynthetic genes, which is increased during the fruit ripening process. Additionally, the exogenous application of $\mathrm{BR}$ promotes banana fruit ripening due to the acceleration of MaACS1, MaACO13, and MaACO14 expression, and consequently, ethylene production occurs, confirming the action of BZR proteins as transcriptional repressors of ethylene biosynthesis [159].

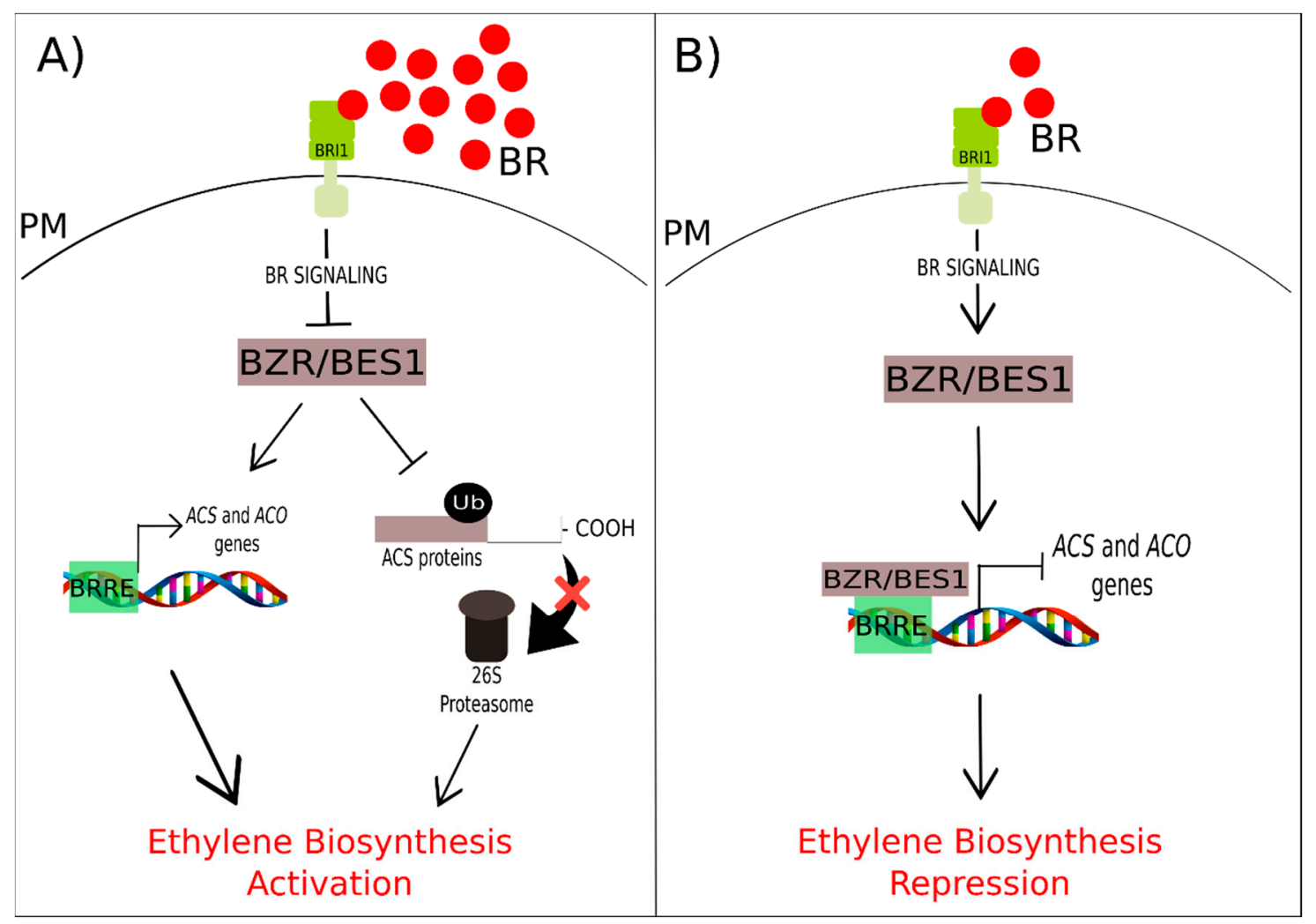

Figure 6. A general simplified model of BR and ethylene cross-talk. The perception of BR begins in its receptor BRASSINOSTEROID INSENSITIVE 1 (BRI1) which activates BR signaling, which, in turn, controls ethylene biosynthesis in a dose-dependent manner. (A) High levels of BR decrease the activity of BRASSINAZOLE RESISTANT 1/BRI1-EMS SUPPRESSOR 1 (BZR1/BES1), the major transcription factors of the BR signaling pathway while enhancing the stability of the 1-aminocyclopropane-1-carboxylic acid (ACC)-synthase enzyme (ACS) proteins by preventing its degradation by the $26 \mathrm{~S}$ proteasome and consequently, activating ethylene biosynthesis. (B) Low levels of BR increase the activity of BZR1/BES1, which, in turn, bind to the promoter of the ACC-synthase (ACS) and $A C C$-oxidase $(A C O)$ genes, inhibiting their transcription and consequently, repressing ethylene biosynthesis. PM represents the plasma membrane.

The application of exogenous BR can also accelerate postharvest ripening, enhancing the development of quality attributes and consequently, promoting ethylene production in Solanum lycopersicum by increasing transcriptional levels of ACS2 and ACS4 genes [160]. Tomato fruits with enhanced BR levels or BR signaling due to overexpression of the BR biosynthetic gene DWARF and the signaling gene BRI1 showed elevated ethylene production and quick-ripening, respectively [161,162]. On the other hand, tomato plants silenced for the BRI1 gene and insensitive to BR presented no changes in ethylene accumulation, ACC content, and ACS and ACO activities during BR treatment, reinforcing 
that BRI1 downstream components may be involved in ethylene accumulation [163], as also suggested by Lv et al. 2018 [158].

Ethylene is also known to be involved in a range of stress responses, such as heat stress [164] and pathogen and pest attacks [165]. Studies using mutants that are deficient and insensitive to ET showed higher thermal and salt tolerance when 24-epibrassinolide (EBR) was applied. EBR was capable of increasing the survival rates of the ET-insensitive mutant ein 2 under heat stress in Arabidopsis plants. Moreover, the treatment of Brassica napus seeds with EBR reduced the inhibition ein 2 mutant germination under salt stress, reverting this line's hypersensitivity to salt to a level similar to those of WT plants [166].

Lettuce plants present high emission of ET and an increase in ACC content during salt stress [167]. However, the increase in ethylene production under salt stress leads to the inhibition of plant growth and induction of senescence and consequently, premature death [168]. The treatment of lettuce plants under salt stress with DI-31, a brassinosteroid analog, was shown to be capable of reducing the ACC content and consequently, ET production, avoiding premature death, alleviating weight loss, and showing a good protective effect of BR against salinity.

\subsection{Brassinosteroids and Abscisic Acid}

Abscisic acid (ABA) is a phytohormone that is involved in a wide range of plant responses and is essential for plant development and survival. The hormone acts as a major abiotic stress sensor, leading to protective responses such as stomatal closure, seed dormancy, and inhibition of growth and germination [169-173]. Even in the early stages of plant development, ABA drives stress tolerance and/or avoidance mechanisms, helping plants to survive in adverse conditions [174].

The serine-threonine kinases SnRK2.2/2.3/2.6 (SNF1-related protein kinases) play a central role in the ABA pathway response as positive regulators of ABA signaling [173,175-177]. The kinases regulate the expression of stress-responsive genes and transcription factors, leading to ABA-related responses. The kinases' activity is modulated by their interactions with PHOSPHATASE 2C (PP2C), which inactivates SnRK2s by dephosphorylation [178]. In the presence of the hormone, the complex formed by ABA and PYL/PYR/RCAR receptors inactivates the phosphatase by blocking the substrate's entry [179-183].

Despite the essential roles of PP2C and SnRK2s in activating ABA responses, their effects in plant cells are influenced by cross-talk with other phytohormones. For example, seed dormancy is affected by the interplay of abscisic acid with gibberellins and ethylene [184]. Also, stomatal movement is regulated under stress by jasmonic acid, cytokinins, ethylene, auxin, and also, brassinosteroids [185,186]. In general, under favorable conditions, the cross-talk between growth-related hormones and ABA results in the attenuation of ABA-related responses by diverse molecular mechanisms, allowing plant growth and development.

The antagonism between ABA and the growth-related hormone brassinosteroid has been known for several years. The negative cross-talk between these hormones has been observed during seed germination, early seedling development, root growth, and stomatal closure $[153,187]$. Moreover, mutants with defective BR signaling (i.e.; bin2-1, bri1, constitutive photomorphogenesis and dwarfism (cpd), and de-etiolated-2 mutant (det2)) have enhanced ABA sensibility during seed germination, early seedling development, and/or primary root formation [96,187-189]. Despite all these observations, the molecular mechanism behind the negative cross-talk remained poorly understood until recently.

Essentially, ABA and BR antagonism includes two types of regulation: post-translational modification at the protein level and transcriptional repression at the gene level. Regarding protein-protein regulation, phosphorylation and dephosphorylation events play a key role in ABA-BR cross-talk. Similar to the ABA signaling pathway, the activity of kinases and phosphatases is crucial to brassinosteroid sensing and responses. The presence of brassinosteroid triggers the activation of the BRI1 kinase-like receptor, the kinases BAK1 and BRI1 and the phosphatase BSU1. This phosphatase is responsible for the dephosphorylation of the kinase BIN2, a major repressor of BR signaling [190]. 
A considerable body of evidence indicates that BIN2 is one of the key players in ABA-BR cross-talk. This kinase can interact and phosphorylate Arabidopsis SnRK2.2 and SnRK2.3 in vitro [191]. BIN2-mediated phosphorylation was shown to increase SnRK2.3 activity in vitro. While the in vivo overexpression of SnRK2.3 caused ABA hypersensitivity, plants overexpressing SnRK2.3 ${ }^{\mathrm{T} 180 \mathrm{~A}}$ presented sensibility to ABA at levels similar to WT plants. These data suggest a role of T180 phosphorylation in ABA signaling in vivo.

BIN2 activity also affects another ABA pathway element downstream of SnRK2s, the basic leucine-zipper (bZIP) transcription factor ABA Insensitive 5 (ABI5). In the presence of ABA, ABI5 regulates seed germination, and seedling growth, leading to seed dormancy and growth arrest responses [192-194]. Moreover, ABI5 activates LATE EMBRYOGENESIS ABUNDANT (LEA) genes in vegetative tissues [194]. A recent study showed that ABI5 interacts with BIN2, which then phosphorylates ABI5 in vitro [195]. In vivo, seeds from the gain-of-function bin2 mutant (bin2-1) presented higher expression of ABI5 target genes during ABA-treatment compared to the triple knockout mutant (bin2-3 bil1 bil2). The effect of BIN2 on ABI5 phosphorylation and target regulons expression indicates that BIN2 might modulate ABA signaling during seed germination and early seed development.

Despite all evidence showing some ABA pathway key elements are targets of BIN2, a recent study suggests that ABI1 and ABI2 [166] might regulate kinase activity [196]. Overexpression of the PP2C family phosphatases ABI1 and ABI2 in Arabidopsis resulted in decreased expression of the gene markers of BR suppression: $\mathrm{CPD}$ and DWF4. Moreover, phosphatase overexpression led to the accumulation of BES1 in its dephosphorylated form. Similar results were previously observed in abi1 and abi2 mutants after ABA treatment [153]. The direct interactions between ABI1, ABI2, and BIN2 could be the mechanism behind these effects: the BR-repressor BIN2 is dephosphorylated by the phosphatases, leading to the accumulation of active BES1 [196]. This mechanism may also explain why only BIN2 extracted from ABA-treated seedlings can phosphorylate ABI5 in vitro [195].

Aside from BIN2, the kinase BAK1 also seems to be involved in ABA-BR cross-talk. A recent study showed that BAK1 can interact with and phosphorylate SnRK2.6 in vitro [197]. As the kinase SnRK2.6 is the primary regulator of stomatal closure [169-171], the lack of BAK1-mediated activation of SnRK2.6 could explain the increased water loss by transpiration observed in bak1-3 mutants, even during ABA treatment [197].

In addition to protein interactions and post-translational modification, ABA-BR cross-talk also comprises mechanisms of regulation at the transcriptional level. Real-time quantitative reverse transcription-PCR (qRT-PCR) analysis revealed low expression of the ABA-related transcription factors-ABFs, $A B I 3$, and $A B I 5$-in the gain-of-function mutant bes1-D seedlings [198]. On the other hand, bes1 knockout mutant (bes $1^{k o}$ ) seedlings displayed high expression of the same transcription factors. Additionally, this mutant presented an enhanced ABA response during root growth and seed germination compared to WT plants. The negative role of BES1 in the ABA signaling pathway relies on the interaction of BES1 with TOPLESS (TPL)/HISTONE DEACETYLASE 19 (HDAC19). Once bound to the $A B I 3$ promoter, $\mathrm{BES1}$ represses $A B I 3$ expression through histone deacetylation by assembling the TPL-HDAC19 complex. As BES1 cannot interact with the $A B I 5$ promoter, the decreased expression of this ABA transcription factor observed in bes1- $D$ is a consequence of the repression of the upstream element $A B I 3$ [192,198].

The direct inhibition of $A B I 5$ expression seems to be controlled by the BZR1 transcription factor. The BR-induced transcription factor binds to G-box sequences present in the $A B I 5$ promoter, reducing their expression [199]. The regulation of $A B I 5$ by BZR1 could be the cause of the $A B I 5$ downregulation in the gain-of-function $b r z 1-1 D$ mutants after ABA treatment. Therefore, the ABA insensibility of bzr1-1D mutants in root growth assays might be a consequence of ABI5 repression by BZR1, and this could be suppressed by ABI5 overexpression.

Recent findings suggest that ABA-BR cross-talk involves multiple players acting on two fronts: modulation of protein activity and regulation of gene expression. In summary, under optimal 
conditions, brassinosteroids trigger $\mathrm{BR}$ cascade activation and antagonize $\mathrm{ABA}$ responses by decreasing $A B I 3$ and $A B I 5$ expression during seed germination and seed growth (Figure 7A) [198,199]. The absence of ABA triggers BR responses by repressing BIN2 through PP2C ABI1 and ABI2 phosphatases [196]. However, during BR signaling repression, BIN2 stimulates and enhances ABA responses through direct phosphorylation of SnRK2.3 and ABI5, leading to ABA-modulated seed dormancy and seedling growth arrest responses [191,195]. Under the same conditions, BAK1 increases stomata responses by SnRK2.6 phosphorylation (Figure 7B) [197].

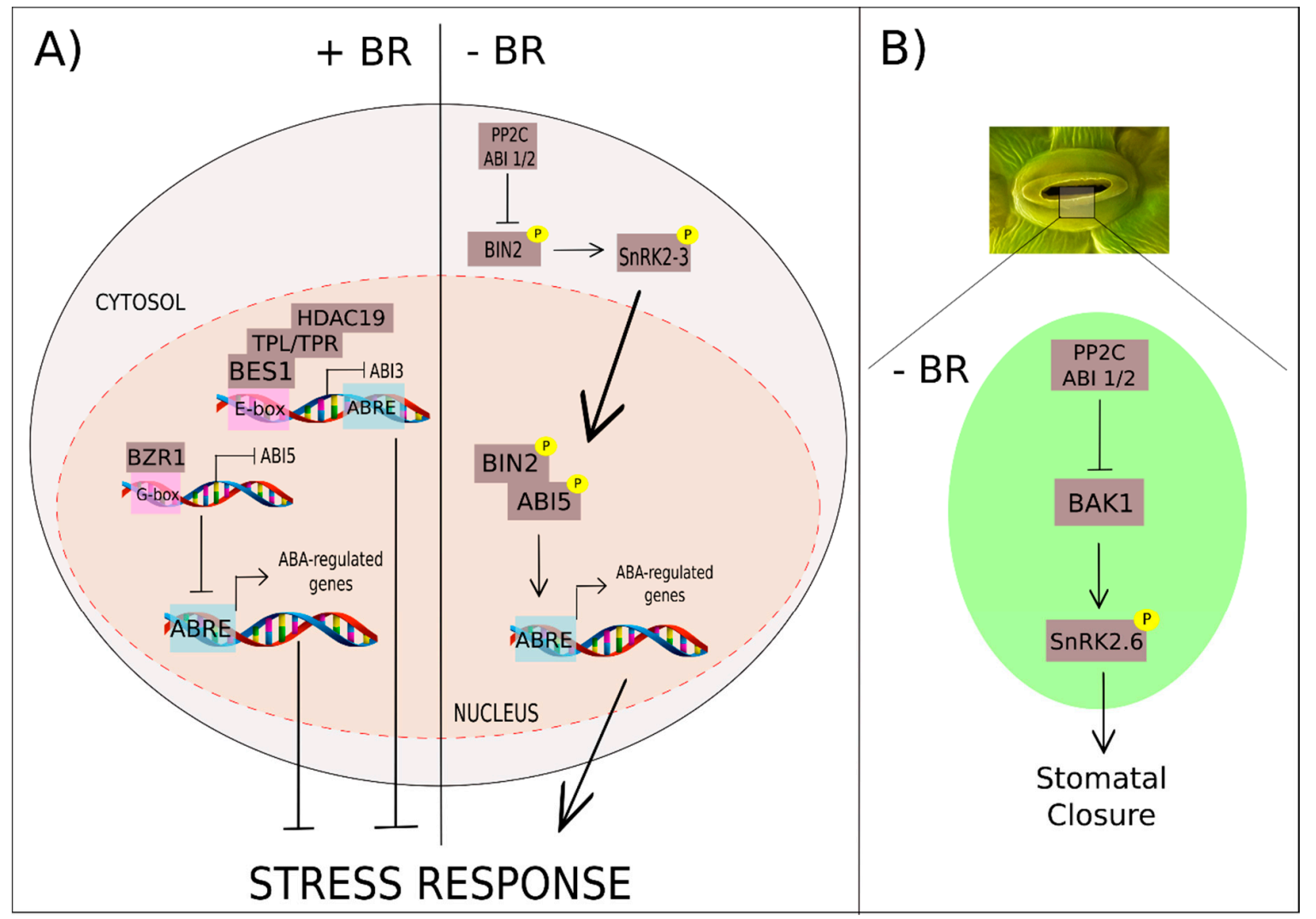

Figure 7. $\mathrm{BR}$ and $\mathrm{ABA}$ cross-talk relies on protein activity modulation and gene expression regulation. (A) In the presence of BR, the complex formed by BRI1-EMS SUPPRESSOR 1 (BES1), TOPLESS/(TPL/TPR) and HISTONE DEACETYLASE 19 (HDAC19) inhibits ABA Insensitive 3 (ABI3) expression by interacting with E-box promoter sequences. The transcription factor BRASSINAZOLE RESISTANT 1 (BZR1) interacts with the G-box sequences of the $A B I 5$ promoter, leading to gene repression. Repression of the $A B I 3$ and $A B I 5$ genes results in lower expression of ABA-regulated genes and decreased stress responses. At low levels of BR, stress responses are stimulated by SnRK2.3 activation by BRASSINOSTEROID-INSENSITIVE 2 (BIN2). Additionally, the BR-repressor BIN2 phosphorylates the transcription factor $A B I 5$, resulting in the expression of ABA-related genes. (B) In guard cells, BRI1-ASSOCIATED RECEPTOR KINASE 1 (BAK1) phosphorylates the kinase SnRK2.6 at low levels of $\mathrm{BR}$, driving stomatal closure responses. At low levels of ABA, the PHOSPHATASE 2C (PP2C) phosphatase ABI1 and ABI2 repress SnRK2.6 phosphorylation by BAK1 and also the phosphorylation of SnRK2.3 by BIN2, decreasing stress responses related to ABA-BR cross-talk.

Despite the substantial evidence supporting the molecular mechanism behind ABA-BR cross-talk, key points remain to be clarified. The previously reported lower auto-activation of SnRK2.2 and SnRK2.3 compared to SnRK2.6 suggests the need for activation by an upstream kinase [200]. However, ABA-related SnRK2s have been under investigation for several years, and different studies have shown that kinase auto-activation is sufficient for kinase activity and activation of downstream ABA-related targets [175,200-202]. In this sense, further studies are required to elucidate the importance of the 
brassinosteroid kinases BIN2 and BAK1 in SnRK2s activation and their roles in the ABA response in vivo. Additionally, the understanding of the interplay between brassinosteroid and ABA network elements in particular tissues and plant developmental stages, considering protein spatial distribution and expression, represents a challenge for future studies [192].

\subsection{Brassinosteroids and Jasmonic and Salicylic Acids}

Plants present a range of defense mechanisms whose costs represent a tradeoff between growth and immunity [203-206], in which phytohormones fulfill central roles in protection against biotic stressors agents. Studies have already proven that BR can induce disease resistance in tobacco (Nicotiana tabacum) and rice (Oryza sativa) [207] in a complex network which involves crucial functions of the receptor BRI1 and its coreceptor BAK1 [203,208-210].

Flagellin 22 (flg22) and chitin are both pathogen- and microbe-associated molecules patterns, also named PAMPs and MAMPs, respectively, which are recognized by the cells of innate immune system as alert signals of invaders. Flg22 binds to its receptor flg-sensing 2 (FLS2), which initiates signals to prevent pathogen proliferation [209-211]. Curiously, the binding of flg22 to FLS2 generates an association and transphosphorylation with BAK1 as happens in BR-induced BRI1 signaling, activating FLS2. The activated FLS2 then phosphorylates BIK1 (BOTRYTIS-INDUCED KINASE 1), a receptor-like cytoplasmic kinase responsible for associating with a flagellin receptor complex, triggering plant innate immunity and transducing the target response [209,212,213]. The association of BAK1 as a coreceptor of both BR-induced BRI1 signaling and flg22-induced FLS2 signaling suggests a possible tradeoff between BR and FLS2 signaling responses mediated by BAKI1.

However, another study suggested the potential existence of BAK-independent immune signaling [214]. Arabidopsis plants treated with both exogenous BR and flg22 showed decrease of flg22-induced MAMP-triggered immunity responses (MTI) by BR. However, on the other hand, flg22 did not affect the BR-induced responses. Additionally, when BR and flg22 were applied separately, they induced distinct gene profiles and biological responses (i.e.; the treatment with flg22 induced the stress markers ROS and MAPKs (mitogen activated protein kinases), which were not observed in plants treated only with BR). These data suggest the inhibition of FLS2-mediated immune signaling by BR, independently of a complex formation with its coreceptor BAK1 and associated downstream phosphorylation when different pools of BAK1 exist and are not interchangeable: the BAK1 recruited by FL2S complex is different from BAK1 recruited by BRI1 signaling [214]. Another independent study corroborated these ideas by providing evidence that the association between BRs and MTI responses depends on the endogenous levels of BR and BRI [215]. A possible mechanism to explain the relation of BR to plant innate immunity is represented in Figure 8.

The importance of jasmonic acid (JA) and salicylic acid (SA) for the plant innate immune system is well characterized [216,217]. These hormones generate and transmit distinct defense signals which are capable of influencing each other through a complex network of synergistic and antagonistic interactions $[218,219]$, allowing the plant to efficiently create a quick and precise defense reaction to causal agents of many types of biotic stress. Previous studies have already shown a mutually antagonistic activity of JA and SA in plant innate immunity [220-222]. Exogenous application of JA can dramatically decrease the SA content in rice, which suggests that JA can suppress the SA pathway [223]. However, recent studies revealed a diverse and complex interplay between BR, JA, and SA.

A negative role of $\mathrm{BR}$ in the defense against brown planthopper (BPH, Nilaparvata lugens) was observed in rice (Oryza sativa). BPH infestation suppressed the BR pathway, decreasing the expression of signaling genes (BRI1 and BZR1) and the BR concentration, while successively activating SA and JA pathways. Moreover, the application of exogenous BR downregulated the expression of genes related to the SA pathway, such as the biosynthetic genes ICS1 and PAL, and reduced SA content, while it upregulated genes related to the JA pathway, like MYC2, AOS2, and LOX1, and increased the JA content during BPH infestation in WT plants [224]. However, this work also observed that BR-mediated suppression of the SA pathway might be associated with the JA pathway. To further 
corroborate this fact, JA-deficient mutant $\circ g 1$ and JA-insensitive mutant col1-18 were submitted to BR exogenous application. The transcription levels of ICS1 and PAL, two SA biosynthetic genes, were not suppressed and SA levels did not decrease as observed in WT plants upon BPH infestation. A similar response was observed in coi1-18 mutants, but in this case, the transcription levels of both ICS1 and PAL as well as the SA concentration increased. These results collectively suggest that JA might participate in the BR-mediated suppression of the SA pathway, reinforcing this antagonistic response.

Curiously, although BR has been suggested as a negative regulator of innate immunity in plants $[132,225,226]$, it has also been found to positively regulate the defense against the chewing herbivore Manduca sexta and the cell-content feeder Thrips tabaci $[227,228]$. These divergent scenarios may be associated with the type of plant tissue affected (root and shoot) and the biotic stressor agent (microbial, virus, insect, necrotrophic, or biotrophic agents); thus, it is very difficult to define a general model of the role of BRs in plant innate immunity and consequently, for BR and JA/SA cross-talk. Furthermore, each plant species, even single plants in the same species, are singular organisms which present different growth-defense trade-offs as a result of resource restriction and these trade-offs are regulated by phytohormone cross-talk in different ways [229].

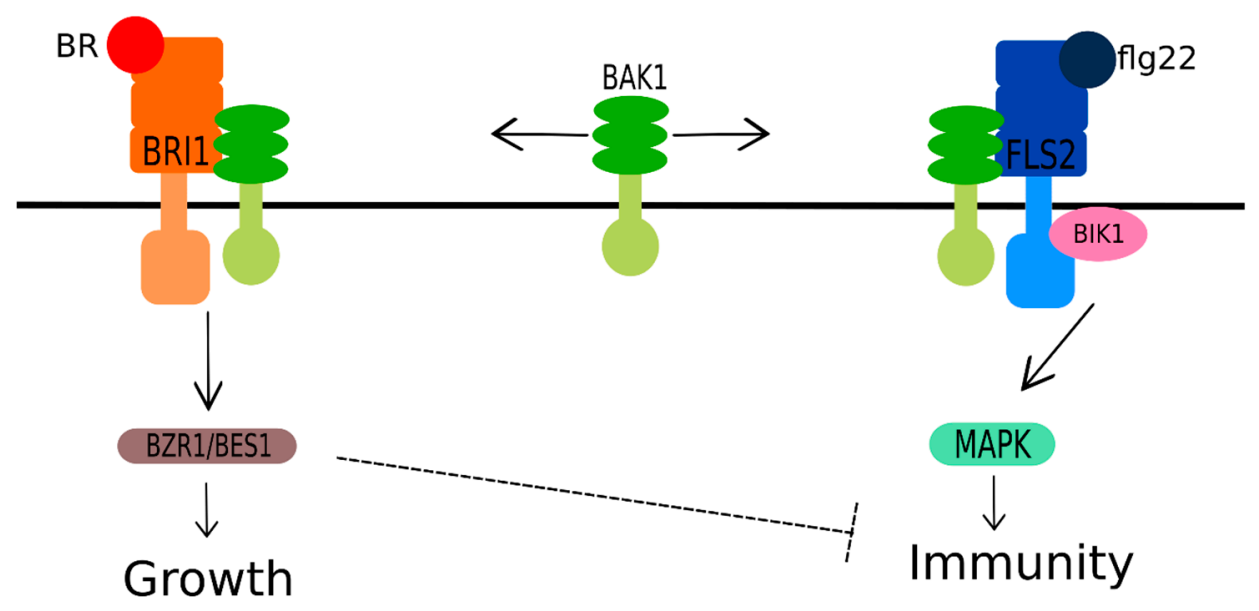

Figure 8. A suggested model of brassinosteroid (BR) regulation of immunity at multiple levels. BAK1 (BRI1-ASSOCIATED RECEPTOR KINASE 1) is considered to mediate the growth and immunity tradeoff because it serves as a coreceptor for both BR-mediated responses via BRI1 and innate immunity mediated responses via flg-sensing 2 (FLS2). The scheme suggests an inhibition of FLS2-mediated immune signaling by BR, independent of complex formation with coreceptor BAK1, when the inhibition occurs downstream of BAK1. BRI1 (BRASSINOSTEROID-INSENSITIVE 1) represents a BR receptor; flg22 (flagellin 22) is a type of pathogen- and microbe-associated molecule pattern (MAMP/PAMP); FLS2 (flg-sensing2) is a flg22 receptor; BIK1 (BOTRYTIS-INDUCED KINASE 1) is a coreceptor of FLS2; BZR1/BES1 (BRASSINAZOLE RESISTANT 1/BRI1-EMS SUPPRESSOR 1, respectively) are the major transcriptional factors of the BR signaling pathway; MAPKs (mitogen activated protein kinases) are a class of marker proteins which indicate various stress conditions.

\subsection{Brassinosteroids and Strigolactones}

Strigolactones (SLs) are a recently discovered group of terpenoid phytohormones that are related to the control of shoot branching [230]. One of the most important signaling components discovered in Arabidopsis is MAX2 (More Axillary Growth Locus 2), which functions to inhibit plant shoot branching [231]. MAX2 constantly interacts with BZR1/BES1 through the PEST domain to mediate their degradation in Arabidopsis. The exogenous application of SL induced the degradation of both BR transcription factors mediated by MAX2, and consequently, inhibited shoot branching. Thereby, the interaction between SL and BR may control developmental processes by modulating the MAX2-mediated stability of BZR1 and BES1 [231]. Until now, there has been little data on the SL 
signaling pathway. It is expected that advances in the research of this new class of phytohormone will more clearly explain the hormonal cross-talk between SL and BR.

\section{Conclusions and Remarks}

As sessile living beings, plants have developed complex mechanisms during their evolution, with phytohormones playing key regulatory roles. The interplay of phytohormones may be used in management and genetic engineering to improve several agricultural traits. In the almost 40 years since the discovery of brassinosteroids as the sixth class of plant hormones, continuous effort has been made to elucidate their role in the multiple aspects of plant physiology. It is known that BRs influence several biological processes, such as growth, protein metabolism, cellular transport and signaling, cell wall biosynthesis, the formation of chromatin and cytoskeleton components, stomatal closure, and environmental responses. Due to the complex network between BRs and other phytohormones and the different physiological effects that this implicates in plant homeostasis, achieving a better understanding of hormonal cross-talk as well as the extensive cross-talk between BRs and other hormones about its role in plant growth and development and responses to stress remains a challenge. This review summarized the previous knowledge about the role of BR cross-talk in plant physiology and compiled the recent findings on these interactions.

Author Contributions: The authors confirm their contribution to this work: A.L.G.L.P.; M.A.T.Z.; J.S.S.; and N.B.M. in Conceptualization; A.L.G.L.P.; N.B.M.; M.A.T.Z.; J.S.S.; G.R.; and R.G.T. in Writing-Original Draft Preparation and Writing-Review \& Editing; and M.M. and N.B.M. in Review and Supervision.

Funding: This work was funded by São Paulo Research Foundation (FAPESP), research grant 2013/15576-5 (M.M.).

Conflicts of Interest: The authors declare no conflict of interest.

\section{Abbreviations}

$\begin{array}{ll}\text { ABA } & \text { Abscisic Acid } \\ \text { ABI } & \text { ABA Insensitive } \\ \text { ACS } & \text { ACC-SYNTHASE } \\ \text { ACC } & \text { 1-aminocyclopropane-1-carboxylicacid } \\ \text { ACO } & \text { ACC-OXIDASE ABA Insensitive } \\ \text { AOS2 } & \text { ALLENE OXIDE SYNTHASE 1 } \\ \text { ARF } & \text { AUXIN RESPONSE FACTOR } \\ \text { AUX } & \text { Auxin } \\ \text { AUX/IAA } & \text { AUXIN/INDOLE ACETIC ACID } \\ \text { AuxREs } & \text { Auxin-responsive DNA Elements } \\ \text { BAK1 } & \text { BRI1-ASSOCIATED RECEPTOR KINASE 1 } \\ \text { BES1/BZR2 } & \text { BRI1-EMS SUPPRESSOR 1 } \\ \text { BIK1 } & \text { BOTRYTIS-INDUCED KINASE 1 } \\ \text { BIN2 } & \text { BRASSINOSTEROID-INSENSITIVE 2 } \\ \text { BL } & \text { Brassinolide } \\ \text { BPH } & \text { Brown Planthopper } \\ \text { BRI1 } & \text { BRASSINOSTEROID INSENSITIVE 1 } \\ \text { BRs } & \text { Brassinosteroids } \\ \text { BRX } & \text { BREVIS RADIX } \\ \text { BRZ } & \text { Brassinazole } \\ \text { BSKs } & \text { BR-SIGNALING KINASE 1 } \\ \text { BSU1 } & \text { BRI1 SUPPRESSOR 1 } \\ \text { bZIP } & \text { Basic Leucine-Zipper } \\ \text { BZR1 } & \text { BRASSINAZOLE RESISTANT 1 } \\ \text { CDG1 } & \text { CONSTITUTIVE DIFFERENTIAL GROWTH 1 } \\ \text { ChiP } & \text { Chromatin Immunoprecipitation } \\ & \end{array}$




\begin{tabular}{|c|c|}
\hline ChiP-seq & Chromatin Immunoprecipitation-sequencing \\
\hline CKs & Cytokinins \\
\hline CKXs & Cytokinin oxidases/dehydrogenases \\
\hline CPD & CONSTITUTIVE PHOTOMORPHISM AND DWARFISM \\
\hline DWF4 & DWARF 4 \\
\hline EGL3 & Enhancer of Glabra 3 \\
\hline ET & Ethylene \\
\hline Fgl22 & Flagellin 22 \\
\hline FLS2 & Flg-sensing 2 \\
\hline GAs & Gibberellins \\
\hline GID1 & GIBBERELLIN INSENSITIVE DWARF1 \\
\hline GL3 & Glabra 3 \\
\hline HDAC19 & HISTONE DEACETYLASE 19 \\
\hline HYD1 & HYDRA 1 \\
\hline IAA & Indole Acetic Acid \\
\hline ICS1 & ISOCHORISMATE SYNTHASE 1 \\
\hline IPT & Isopentenyltransferases \\
\hline JA & Jasmonic Acid \\
\hline KIB1 & KINK SUPPRESSED IN BZR1-1D \\
\hline LOX1 & LIPOXYGENASE 1 \\
\hline LRR & Leucine Rich Repeat \\
\hline MAMPs & Microbial Associated Molecules Patters \\
\hline MAPKs & Mitogen Activated Protein Kinases \\
\hline MAX2 & More Axillary Growth Locus 2 \\
\hline MTI & MAMP-triggered Immunity \\
\hline NPF & NITRATE TRANSPORTER 1/PEPTIDE TRANSPORTER FAMILY \\
\hline OA & Okadaic Acid \\
\hline PAL & PHENYLALANINE AMMONIUM LYASE \\
\hline PAMPs & Pathogen Associated Molecules Patters \\
\hline PAP1 & Anthocyanin Pigment 1 \\
\hline PP2A & PHOSPHATASE 2A \\
\hline PP2AB' & $\mathrm{PP} \mathrm{AB}^{\prime} \alpha$ and $\mathrm{PP} 2 \mathrm{AB}^{\prime} \beta$ subunits \\
\hline PP2C & PHOSPHATASE 2C \\
\hline QC & Quiescence Center \\
\hline qRT-PCR & Real-time Quantitative Reverse Transcription-PCR \\
\hline RLK & Receptor-like kinase \\
\hline ROS & Reactive Oxygen Species \\
\hline SA & Salicylic Acid \\
\hline SAM & Shoot Apical Meristem \\
\hline $\mathrm{SAM}^{2}$ & S-adenosyl methionine \\
\hline SBI1 & SUPPRESSOR OF BRI1 \\
\hline SLs & Strigolactones \\
\hline SLR1 & SLENDER RICE 1 \\
\hline TIR1/AFB & TRANSPORT INHIBITOR RESPONSE1/AUXIN SIGNALING F-BOX \\
\hline TPL & TOPLESS \\
\hline WT & Wilt-type \\
\hline
\end{tabular}

\section{References}

1. Gustafson, F.G. Parthenocarpy Induced by Pollen Extracts. Am. J. Bot. 1937, 24, 102-107. [CrossRef]

2. Gustafson, F.G. Inducement of Fruit Development by Growth-Promoting Chemicals. Proc. Natl. Acad. Sci. USA 1936, 22, 628-636. [CrossRef] [PubMed]

3. Mitchell, J.W.; Whitehead, M.R. Responses of Vegetative Parts of Plants Following Application of Extract of Pollen from Zea mays. Bot. Gaz. 1941, 102, 770-791. [CrossRef] 
4. Mitchell, J.W.; Skraggs, D.P.; Anderson, W.P. Plant Growth-stimulating Hormones in Immature Bean Seeds. Science 1951, 114, 159-161. [CrossRef] [PubMed]

5. Mitchell, J.W.; Mandava, N.B.; Worley, J.F.; Plimmer, J.R.; Smith, M.V. Brassins-A new family of plant hormones from rape pollen. Nature 1970, 225, 1065-1066. [CrossRef] [PubMed]

6. Mandava, N.B.; Mitchell, J.W. New plant hormones: Chemical and biological investigations. Indian Agric. 1971, 15, 19-31.

7. Steffens, G.L. U.S. Department of Agriculture Brassins Projects: 1970-1980. In Brassinosteroids: Chemistry, Bioactivity and Applications; Cutler, H.G., Yokota, T., Adam, G., Eds.; American Chemical Society: Washington, DC, USA, 1991; pp. 2-17. [CrossRef]

8. Mandava, N.B.; Sidwell, B.A.; Mitchell, J.W.; Worley, J.F. Production of Brassins from Rape Pollen. A Convenient Preparatory Method. Ind. Eng. Chem. Prod. Res. Dev. 1973, 12, 138-139. [CrossRef]

9. Grove, M.D.; Spencer, G.F.; Rohwedder, W.K.; Mandava, N.; Worley, J.F.; Warthen, J.D.; Steffens, G.L.; Flippen-Anderson, J.L.; Cook, J.C., Jr. Brassinolide, a plant growth-promoting steroid isolated from Brassica napus pollen. Nature 1979, 281, 216-217. [CrossRef]

10. Fung, S.; Sidall, J.B. Stereoselective Synthesis of Brassinolide: A Plant Growth Promoting Steroidal Lactone. J. Am. Chem. Soc. 1980, 102, 6580-6581. [CrossRef]

11. Ishiguro, M.; Takatsuto, S.; Morisaki, M.; Ikekawa, N. Synthesis of Brassinolide, a Steroidal Lactone with Plant-growth Promoting Activity. J. Chem. Soc. Chem. Comm. 1980, 20, 962-964. [CrossRef]

12. Thompson, M.J.; Mandava, N.B.; Flippen-Anderson, J.L.; Worley, J.F.; Dutky, S.R.; Robbins, W.E.; Lusby, W. Synthesis of Brassino Steroids: New Plant-Growth-Promoting Steroids. J. Org. Chem. 1979, 44, 5002-5004. [CrossRef]

13. Thompson, M.J.; Meudt, W.J.; Mandava, N.B.; Dutky, S.R.; Lusby, W.R.; Spaulding, D.W. Synthesis of brassinosteroids and relationship of structure to plant growth-promoting effects. Steroids 1982, 39, 89-105. [CrossRef]

14. Thompson, M.J.; Mandava, N.B.; Meudt, W.J.; Lusby, W.R.; Spaulding, D.W. Synthesis and biological activity of brassinolide and its 22 $3,23 \beta$-isomer: Novel plant growth-promoting steroids. Steroids 1981, 38, 567-580. [CrossRef]

15. Sakakibara, M.; Mori, K. Facile synthesis of (22R,23R)-homobrassinolide. Agric. Biol. Chem. 1982, 46, 2769-2779. [CrossRef]

16. Takatsuto, S.; Ying, B.; Morisaki, M.; Ikekawa, N. Microanalysis of brassinolide and its analogs by gas chromatography and gas chromatography-mass spectrometry. J. Chromatogr. A 1982, 239, 233-241. [CrossRef]

17. Takatsuto, S. Brassinosteroids: Distribution in plants, bioassays and microanalysis by gas chromatographymass spectrometry. J. Chromatogr. A 1994, 658, 3-15. [CrossRef]

18. Gamoh, K.; Takatsuto, S. Liquid chromatographic assay of brassinosteroids in plants. J. Chromatogr. A 1994, 658, 17-25. [CrossRef]

19. Mandava, N.B. Plant growth-promoting brassinosteroids. Annu. Rev. Plant Physiol. Plant Mol. Biol. 1988, 39, 23-52. [CrossRef]

20. Cutler, H.G.; Yokota, T.; Adam, G. Brassinosteroids: Chemistry, Bioactivity and Applications; American Chemical Society: Washington, DC, USA, 1991; ISBN 0-8412-2126-X.

21. Khripach, V.A.; Zhabinskii, V.N.; de Groot, A.E. Brassinosteroids—A New Class of Plant Hormones, 1st ed.; Academic Press: San Diego, CA, USA, 1999; ISBN 0-12-406360-8.

22. Sakurai, A.; Yokota, T.; Clouse, S.D. Brassinosteroids-Steroidal Plant Hormones, 1st ed.; Springer: Tokyo, Japan, 1999; ISBN 978-4-431-70214-6.

23. Hayat, S.; Ahmad, A. Brassinosteroids: Bioactivity and Crop Productivity, 1st ed.; Kluwer Academic: Dordrecht, The Netherlands, 2003; ISBN 1-4020-1710-3.

24. Pereira-Netto, A.B. Brassinosteroids Practical Applications in Agriculture and Human Health, 1st ed.; Bentham Science: Sharjah, UAE, 2012; ISBN 978-1-60805-298-1.

25. Zullo, M.A.T. Brassinosteroids and Related Compounds, 1st ed.; Lambert Academic Publishing: Beau Bassin, Mauritius, 2018; ISBN 978-3-330-34627-7.

26. Zullo, M.A.T.; Adam, G. Brassinosteroid phytohormones-Structure, bioactivity and applications. Braz. J. Plant Physiol. 2002, 14, 143-181. [CrossRef]

27. Mitchell, J.W.; Gregory, L.E. Enhancement of overall plant growth, a new response to brassins. Nat. New Biol. 1972, 239, 253-254. [CrossRef] 
28. Gregory, L.E. Acceleration of Plant Growth through Seed Treatment with Brassins. Am. J. Bot. 1981, 68, 586-588. [CrossRef]

29. Mitchell, J.W.; Mandava, N.B.; Worley, J.F.; Drowne, M.E. Fatty Hormones in Pollen and Immature Seeds of Bean. J. Agric. Food Chem. 1971, 19, 391-393. [CrossRef]

30. Yopp, J.H.; Colclasure, G.C.; Mandava, N.B. Effects of Brassin-Complex on Auxin and Gibberellin Mediated Events in the Morphogenesis of the Etiolated Bean Hypocotyl. Physiol. Plant. 1979, 46, 247-254. [CrossRef]

31. Krizek, D.T.; Worley, L.J.F. The influence of spectral quality on the internodal response of intact bean plants to brassins. Physiol. Plant. 1981, 51, 259-264. [CrossRef]

32. Yopp, J.H.; Mandava, N.B.; Sasse, J.M. Brassinolide, a growth-promoting steroidal lactone. I. Activity in selected auxin bioassays. Physiol. Plant. 1981, 53, 445-452. [CrossRef]

33. Yopp, J.H.; Mandava, N.B.; Thompson, M.J.; Sasse, J.M. Activity of brassinosteroid in selected bioassays in combination with chemicals known to synergize or retard responses to auxin and gibberellin [Dwarf bean, sunflower, adsuki bean, mung bean]. Proc. Plant Growth Regul. Soc. Am. 1981, 8, 138-145.

34. Mandava, N.B.; Sasse, J.M.; Yopp, J.H. Brassinolide, a growth-promoting steroidal lactone: II. Activity in selected gibberellin and cytokinin bioassays. Physiol. Plant. 1981, 53, 453-461. [CrossRef]

35. Gregory, L.E.; Mandava, N.B. The activity and interaction of brassinolide and gibberellic acid in mung bean epicotyls. Physiol. Plant. 1982, 54, 239-243. [CrossRef]

36. Schlagnhaufer, C.; Arteca, R.N.; Yopp, J.H. A brassinosteroid-cytokinin interaction on ethylene production by etiolated mung bean segments. Physiol. Plant. 1984, 60, 347-350. [CrossRef]

37. Schlagnhaufer, C.; Arteca, R.N.; Yopp, J.H. Evidence that brassinosteroid stimulates auxin-induced ethylene synthesis in mung bean hypocotyls between S-adenosylmethionine and 1-aminocyclopropane-1-carboxylic acid. Physiol. Plant. 1984, 61, 555-558. [CrossRef]

38. Cohen, J.D.; Meudt, W.J. Investigations on the mechanism of the brassinosteroid response. 1. Indole-3-aceticacid metabolism and transport. Plant Physiol. 1983, 72, 691-694. [CrossRef] [PubMed]

39. Meudt, W.J.; Thompson, M.J.; Bennett, H.W. Investigations on the mechanism of the brassinosteroid response. III. Techniques for potential enhancement of crop production. Proc. Annu. Meet. Plant Growth Regul. Soc. Am. 1983, 10, 312-318.

40. Meudt, W.J.; Thompson, M.J. Investigations on the mechanism of the brassinosteroid response. II. A modulation of auxin action. Proc. Annu. Meet. Plant Growth Regul. Soc. Am. 1983, 10, 306-311.

41. Sasse, J.M. The place of brassinolide in the sequential response to plant growth regulators in elongating tissue. Physiol. Plant. 1985, 63, 303-308. [CrossRef]

42. Hewitt, F.R.; Hough, T.; O'Neill, P.; Sasse, J.M.; Williams, E.G.; Rowan, K.S. Effect of brassinolide and other growth regulators on the germination and growth of pollen tubes of Prunus avium using a multiple hanging-drop assay. Aust. J. Plant Physiol. 1985, 12, 201-211. [CrossRef]

43. Clouse, S.D.; Zurek, D. Molecular analysis of brassinolide action in plant growth and development. ACS Symp. Ser. Am. Chem. Soc. 1991, 122-140. [CrossRef]

44. Nomura, T.; Nakayama, M.; Reid, J.B.; Takeuchi, Y.; Yokota, T. Blockage of Brassinosteroid Biosynthesis and Sensitivity Causes Dwarfism in Garden Pea. Plant Physiol. 1997, 113, 31-37. [CrossRef]

45. Li, J.; Chory, J. A Putative Leucine-Rich Repeat Receptor Kinase Involved in Brassinosteroid Signal Transduction. Cell. 1997, 90, 929-938. [CrossRef]

46. Asami, T.; Min, Y.K.; Nagata, N.; Yamagishi, K.; Takatsuto, S.; Fujioka, S.; Murofushi, N.; Yamaguchi, I.; Yoshida, S. Characterization of brassinazole, a triazole-type brassinosteroid biosynthesis inhibitor. Plant Physiol. 2000, 123, 93-99. [CrossRef]

47. Yoshida, S. Regulators of Plant Signal Transduction for Healthy Growth. J. Pestic. Sci. 2000, 25, 441-445. [CrossRef]

48. Hothorn, M.; Belkhadir, Y.; Dreux, M.; Dabi, T.; Noel, J.P.; Wilson, I.A.; Chory, J. Structural basis of steroid hormone perception by the receptor kinase BRI1. Nature 2011, 474, 467-471. [CrossRef] [PubMed]

49. She, J.; Han, Z.; Kim, T.-W.; Wang, J.; Cheng, W.; Chang, J.; Shi, S.; Wang, J.; Yang, M.; Wang, Z.-Y.; et al. Structural insight into brassinosteroid perception by BRI1. Nature 2011, 474, 472-476. [CrossRef]

50. Clouse, S.D. A History of Brassinosteroid Research from 1970 through 2005: Thirty-Five Years of Phytochemistry, Physiology, Genes, and Mutants. J. Plant Growth Regul. 2015, 34, 828-844. [CrossRef]

51. Bajguz, A. Metabolism of brassinosteroids in plants. Plant Physiol. Biochem. 2007, 45, 95-107. [CrossRef] 
52. Clouse, S.D. Brassinosteroid Signal Transduction: From Receptor Kinase Activation to Transcriptional Networks Regulating Plant Development. Plant Cell 2011, 23, 1219-1230. [CrossRef] [PubMed]

53. Vriet, C.; Russinova, E.; Reuzeau, C. Boosting Crop Yields with Plant Steroids. Plant Cell 2012, $24,842-857$. [CrossRef] [PubMed]

54. Verhoef, N.; Yokota, T.; Shibata, K.; De Boer, G.J.; Gerats, T.; Vandenbussche, M.; Koes, R.; Souer, E. Brassinosteroid biosynthesis and signalling in Petunia hybrida. J. Exp. Bot. 2013, 64, 2435-2448. [CrossRef]

55. Sun, Y.; Fan, X.Y.; Cao, D.M.; Tang, W.; He, K.; Zhu, J.Y.; He, J.X.; Bai, M.Y.; Zhu, S.; Oh, E.; et al. Integration of Brassinosteroid Signal Transduction with the Transcription Network for Plant Growth Regulation in Arabidopsis. Dev. Cell 2010, 19, 765-777. [CrossRef]

56. Li, J.; Jin, H. Regulation of brassinosteroid signaling. Trends Plant Sci. 2007, 12, 37-41. [CrossRef]

57. Kim, T.W.; Wang, Z.Y. Brassinosteroid Signal Transduction from Receptor Kinases to Transcription Factors. Annu. Rev. Plant Biol. 2009, 61, 681-704. [CrossRef]

58. Yang, C.J.; Zhang, C.; Lu, Y.N.; Jin, J.Q.; Wang, X.L. The mechanisms of brassinosteroids' action: From signal transduction to plant development. Mol. Plant 2011, 4, 588-600. [CrossRef] [PubMed]

59. Shiu, S.; Karlowski, W.M.; Pan, R.; Tzeng, Y.; Mayer, K.F.X.; Li, W. Comparative Analysis of the Receptor-Like Kinase Family in Arabidopsis and Rice. Plant Cell 2004, 16, 1220-1234. [CrossRef]

60. Belkhadir, Y.; Chory, J. Brassinosteroid signaling: A paradigm for steroid hormone signaling from the cell surface. Science 2006, 314, 1410-1411. [CrossRef] [PubMed]

61. Li, J.; Wen, J.; Lease, K.A.; Doke, J.T.; Tax, F.E.; Walker, J.C. BAK1, an Arabidopsis LRR receptor-like protein kinase, interacts with BRI1 and modulates brassinosteroid signaling. Cell 2002, 110, 213-222. [CrossRef]

62. Li, J.; Nam, K.H. Regulation of Brassinosteroid Signaling by a GSK3/SHAGGY-like Kinase. Science 2002, 295, 1299-1301. [CrossRef]

63. Russinova, E.; Borst, J.-W.; Kwaaitaal, M.; Caño-Delgado, A.; Yin, Y.; Chory, J.; De Vries, S.C. Heterodimerization and Endocytosis of Arabidopsis Brassinosteroid Receptors BRI1 and AtSERK3 (BAK1). Plant Cell Online 2004, 16, 3216-3229. [CrossRef] [PubMed]

64. Wang, X.; Goshe, M.B.; Soderblom, E.J.; Phinney, B.S.; Kuchar, J.A.; Li, J.; Asami, T.; Yoshida, S.; Huber, S.C.; Clouse, S.D. Identification and functional analysis of in vivo phosphorylation sites of the 723 Arabidopsis BRASSINOSTEROID-INSENSITIVE1 receptor kinase. Plant Cell 2005, 17, 1685-1703. [CrossRef] [PubMed]

65. Wang, X.; Kota, U.; He, K.; Blackburn, K.; Li, J.; Goshe, M.B.; Huber, S.C.; Clouse, S.D. Sequential Transphosphorylation of the BRI1/BAK1 Receptor Kinase Complex Impacts Early Events in Brassinosteroid Signaling. Dev. Cell 2008, 15, 220-235. [CrossRef] [PubMed]

66. Wang, X.; Chory, J. Brassinosteroids Regulate Dissociation of BKI1, a Negative Regulator of BRI1 Signaling, from the Plasma Membrane. Science 2006, 313, 1118-1122. [CrossRef]

67. Jaillais, Y.; Hothorn, M.; Belkhadir, Y.; Jaillais, Y.; Hothorn, M.; Belkhadir, Y.; Dabi, T.; Nimchuk, Z.L.; Meyerowitz, E.M.; Chory, J. Tyrosine phosphorylation controls brassinosteroid receptor activation by triggering membrane release of its kinase inhibitor service Tyrosine phosphorylation controls brassinosteroid receptor activation by triggering membrane release of its kinase inhibit. Genes Dev. 2011, 25, 232-237. [CrossRef] [PubMed]

68. Bai, M.-Y.; Zhang, L.-Y.; Gampala, S.S.; Zhu, S.-W.; Song, W.-Y.; Chong, K.; Wang, Z.-Y. Functions of OsBZR1 and 14-3-3 proteins in brassinosteroid signaling in rice. Proc. Natl. Acad. Sci. USA 2007, 104, 13839-13844. [CrossRef] [PubMed]

69. Gampala, S.S.; Kim, T.W.; He, J.X.; Tang, W.; Deng, Z.; Bai, M.Y.; Guan, S.; Lalonde, S.; Sun, Y.; Gendron, J.M.; et al. An Essential Role for 14-3-3 Proteins in Brassinosteroid Signal Transduction in Arabidopsis. Dev. Cell 2007, 13, 177-189. [CrossRef]

70. Ryu, H.; Kim, K.; Cho, H.; Park, J.; Choe, S.; Hwang, I. Nucleocytoplasmic Shuttling of BZR1 Mediated by Phosphorylation Is Essential in Arabidopsis Brassinosteroid Signaling. Plant Cell Online 2007, 19, 2749-2762. [CrossRef] [PubMed]

71. Ryu, H.; Cho, H.; Kim, K.; Hwang, I. Phosphorylation dependent nucleocytoplasmic shuttling of BES1 is a key regulatory event in brassinosteroid signaling. Mol. Cells 2010, 29, 283-290. [CrossRef]

72. Ryu, H.; Kim, K.; Cho, H.; Hwang, I. Predominant actions of cytosolic BSU1 and nuclear BIN2 regulate subcellular localization of bes1 in brassinosteroid signaling. Mol. Cells 2010, 29, 291-296. [CrossRef] 
73. Tang, W.; Kim, T.-W.; Oses-prieto, J.A.; Sun, Y.; Deng, Z.; Zhu, S.; Wang, R.; Burlingame, A.L.; Wang, Z.-Y. Brassinosteroid-Signaling Kinases (BSKs) mediate signal transduction from the receptor kinase BRI1 in Arabidopsis. Science 2008, 321, 557-560. [CrossRef] [PubMed]

74. Kim, T.W.; Guan, S.; Burlingame, A.L.; Wang, Z.Y. The CDG1 Kinase Mediates Brassinosteroid Signal Transduction from BRI1 Receptor Kinase to BSU1 Phosphatase and GSK3-like Kinase BIN2. Mol. Cell 2011, 43, 561-571. [CrossRef] [PubMed]

75. Mora-Garcia, S.; Vert, G.; Yin, Y.H.; Cano-Delgado, A.; Cheong, H.; Chory, J. Nuclear protein phosphatases with Kelch-repeat domains modulate the response to bras sino steroids in Arabidopsis. Genes Dev. 2004, 18, 448-460. [CrossRef]

76. Zhu, J.Y.; Li, Y.; Cao, D.M.; Yang, H.; Oh, E.; Bi, Y.; Zhu, S.; Wang, Z.Y. The F-box Protein KIB1 Mediates Brassinosteroid-Induced Inactivation and Degradation of GSK3-like Kinases in Arabidopsis. Mol. Cell 2017, 66, 648-657. [CrossRef]

77. Wang, Z.Y.; Nakano, T.; Gendron, J.; He, J.; Chen, M.; Vafeados, D.; Yang, Y.; Fujioka, S.; Yoshida, S.; Asami, T.; et al. Nuclear-localized BZR1 mediates brassinosteroid-induced growth and feedback suppression of brassinosteroid biosynthesis. Dev. Cell 2002, 2, 505-513. [CrossRef]

78. Wu, G.; Wang, X.; Li, X.; Kamiya, Y.; Otegui, M.S. Methylation of a Phosphatase Specifies Dephosphorylation and Degradation of Activated Brassinosteroid Receptors. Sci. Signal. 2011, 4, 1-25. [CrossRef]

79. Wei, Z.; Li, J. Brassinosteroids Regulate Root Growth, Development, and Symbiosis. Mol. Plant 2015, 9, 86-100. [CrossRef] [PubMed]

80. Zhao, Y. Auxin Biosynthesis and Its Role in Plant Development. Annu. Rev. Plant Biol. 2010, 61, 49-64. [CrossRef]

81. Nemhauser, J.L.; Mockler, T.C.; Chory, J. Interdependency of brassinosteroid and auxin signaling in Arabidopsis. PLoS Biol. 2004, 2, 1460-1471. [CrossRef] [PubMed]

82. Vert, G.; Walcher, C.L.; Chory, J.; Nemhauser, J.L. Integration of auxin and brassinosteroid pathways by Auxin Response Factor 2. Proc. Natl. Acad. Sci. USA 2008, 105, 9829-9834. [CrossRef] [PubMed]

83. Ljung, K.; Bhalerao, R.P. Sites and homeostatic control of auxin biosynthesis in Arabidopsis during vegetative growth. Plant J. 2001, 28, 465-474. [CrossRef] [PubMed]

84. Ljung, K.; Hull, A.K.; Celenza, J.; Yamada, M.; Estelle, M.; Normanly, J. Sites and Regulation of Auxin Biosynthesis in Arabidopsis Roots. Plant Cell 2005, 17, 1090-1104. [CrossRef] [PubMed]

85. Tian, H.; Lv, B.; Ding, T.; Bai, M.; Ding, Z. Auxin-BR Interaction Regulates Plant Growth and Development. Front. Plant Sci. 2018, 8, 2256. [CrossRef]

86. Wang, D.; Pei, K.; Fu, Y.; Sun, Z.; Li, S.; Liu, H.; Tang, K.; Han, B.; Tao, Y. Genome-wide analysis of the auxin response factors (ARF) gene family in rice (Oryza sativa). Gene 2007, 394, 13-24. [CrossRef]

87. Goda, H.; Sawa, S.; Asami, T.; Fujioka, S.; Shimada, Y.; Yoshida, S. Comprehensive Comparison of 785 Auxin-Regulated and Brassinosteroid-Regulated Genes in Arabidopsis. Plant Physiol. 2004, 134, 1555-1573. [CrossRef]

88. Bargmann, B.O.R.; Vanneste, S.; Krouk, G.; Nawy, T.; Efroni, I.; Shani, E.; Choe, G.; Friml, J.; Bergmann, D.C.; Estelle, M.; et al. A map of cell type-specific auxin responses. Mol. Syst. Biol. 2013, 9. [CrossRef]

89. Jung, J.; Lee, M.; Park, C. A Transcriptional Feedback Loop Modulating Signaling Crosstalks between Auxin and Brassinosteroid in Arabidopsis. Mol. Cells 2010, 449-456. [CrossRef] [PubMed]

90. Tian, C.; Muto, H.; Higuchi, K.; Matamura, T.; Tatematsu, K.; Koshiba, T. Disruption and overexpression of auxin response factor 8 gene of Arabidopsis affect hypocotyl elongation and root growth habit, indicating its possible involvement in auxin homeostasis in light condition. Plant J. 2004, 3, 333-343. [CrossRef]

91. Oh, E.; Zhu, J.; Bai, M.; Arenhart, R.A.; Sun, Y.; Wang, Z. Cell elongation is regulated through a central circuit of interacting transcription factors in the Arabidopsis hypocotyl. eLife 2014, 3, e03031. [CrossRef] [PubMed]

92. Liu, K.; Li, Y.; Chen, X.; Li, L.; Liu, K.; Zhao, H.; Wang, Y.; Han, S. ERF72 interacts with ARF6 and BZR1 to regulate hypocotyl elongation in Arabidopsis. J. Exp. Bot. 2018, 69, 3933-3947. [CrossRef] [PubMed]

93. Zhou, X.Y.; Song, L.; Xue, H.W. Brassinosteroids regulate the differential growth of Arabidopsis hypocotyls through auxin signaling components IAA19 and ARF7. Mol. Plant 2013,6, 887-904. [CrossRef]

94. Zhang, Y.; Liu, Z.; Wang, J.; Chen, Y.; Bi, Y.; He, J. Brassinosteroid is required for sugar promotion of hypocotyl elongation in Arabidopsis in darkness. Planta 2015, 242, 881-893. [CrossRef] [PubMed] 
95. Cho, H.; Ryu, H.; Rho, S.; Hill, K.; Smith, S.; Audenaert, D.; Park, J.; Han, S.; Beeckman, T.; Bennett, M.J.; et al. A secreted peptide acts on BIN2-mediated phosphorylation of ARFs to potentiate auxin response during lateral root development. Nat. Cell Biol. 2014, 16, 66-76. [CrossRef]

96. Clouse, S.D.; Langford, M.; McMorris, T.C. A Brassinosteroid-Insensitive Mutant in Arabidopsis thaliana Exhibits Multiple Defects in Growth and Development. Plant Physiol. 1996, 111, 671-678. [CrossRef]

97. Chaiwanon, J.; Wang, Z.Y. Spatiotemporal brassinosteroid signaling and antagonism with auxin pattern stem cell dynamics in Arabidopsis roots. Curr. Biol. 2015, 25, 1031-1042. [CrossRef]

98. González-García, M.-P.; Vilarrasa-Blasi, J.; Zhiponova, M.; Divol, F.; Mora-García, A.; Russinova, E.; Caño-Delgado, A. Brassinosteroids control meristem size by promoting cell cycle progression in Arabidopsis roots. Stem Cells Dev. 2011, 138, 849-859. [CrossRef] [PubMed]

99. Yin, Y.; Wang, Z.Y.; Mora-Garcia, S.; Li, J.; Yoshida, S.; Asami, T.; Chory, J. BES1 accumulates in the nucleus in response to brassinosteroids to regulate gene expression and promote stem elongation. Cell 2002, 109, 181-191. [CrossRef]

100. Walcher, C.L.; Nemhauser, J.L. Bipartite promoter element required for auxin response. Plant Physiol. 2012, 158, 273-282. [CrossRef] [PubMed]

101. Paponov, I.A.; Teale, W.D.; Trebar, M.; Blilou, I.; Palme, K. The PIN auxin efflux facilitators: Evolutionary and functional perspectives. Trends Plant Sci. 2005, 10, 170-177. [CrossRef] [PubMed]

102. Mouchel, C.F.; Osmont, K.S.; Hardtke, C.S. BRX mediates feedback between brassinosteroid levels and auxin signalling in root growth. Nature 2006, 443, 458-461. [CrossRef] [PubMed]

103. Depuydt, S.; Hardtke, C.S. Hormone Signalling Cross-talk in Plant Growth Regulation. Curr. Biol. 2011, 21, R365-R373. [CrossRef] [PubMed]

104. Binenbaum, J.; Weinstain, R.; Shani, E. Gibberellin Localization and Transport in Plants. Trends Plant Sci. 2018, 23, 410-421. [CrossRef] [PubMed]

105. Hedden, P.; Sponsel, V. A Century of Gibberellin Research. J. Plant Growth Regul. 2015, 34, 740-760. [CrossRef] [PubMed]

106. Yamaguchi, S. Gibberellin Metabolism and its Regulation. Annu. Rev. Plant Biol. 2008, 59, 225-251. [CrossRef] [PubMed]

107. Tal, I.; Zhang, Y.; Jørgensen, M.E.; Pisanty, O.; Barbosa, I.C.R.; Zourelidou, M.; Regnault, T.; Crocoll, C.; Erik Olsen, C.; Weinstain, R.; et al. The Arabidopsis NPF3 protein is a GA transporter. Nat. Commun. 2016, 7. [CrossRef]

108. Kanno, Y.; Oikawa, T.; Chiba, Y.; Ishimaru, Y.; Shimizu, T.; Sano, N.; Koshiba, T.; Kamiya, Y.; Ueda, M.; Seo, M. AtSWEET13 and AtSWEET14 regulate gibberellin-mediated physiological processes. Nat. Commun. 2016, 7. [CrossRef] [PubMed]

109. Rizza, A.; Walia, A.; Lanquar, V.; Frommer, W.B.; Jones, A.M. In vivo gibberellin gradients visualized in rapidly elongating tissues. Nat. Plants 2017, 3, 803-813. [CrossRef] [PubMed]

110. Shani, E.; Weinstain, R.; Zhang, Y.; Castillejo, C.; Kaiserli, E.; Chory, J.; Tsien, R.Y.; Estelle, M. Gibberellins accumulate in the elongating endodermal cells of Arabidopsis root. Proc. Natl. Acad. Sci. USA 2013, 110, 4834-4839. [CrossRef] [PubMed]

111. Davière, J.-M.; Achard, P. Gibberellin signaling in plants. Development 2013, 140, 1147-1151. [CrossRef] [PubMed]

112. Okada, K.; Ito, T.; Fukazawa, J.; Takahashi, Y. Gibberellin Induces an Increase in Cytosolic Ca2+ via a DELLA-Independent Signaling Pathway. Plant Physiol. 2017, 175, 1536-1542. [CrossRef] [PubMed]

113. Koornneef, M.; van der Veen, J.H. Induction and analysis of gibberellin sensitive mutants in Arabidopsis thaliana (L.) heynh. Theor. Appl. Genet. 1980, 58, 257-263. [CrossRef] [PubMed]

114. Li, J.; Nagpal, P.; Vitart, V.; McMorris, T.C.; Chory, J. A role for brassinosteroids in light-dependent development of Arabidopsis. Science 1996, 272, 398-401. [CrossRef]

115. Szekeres, M.; Németh, K.; Koncz-Kálmán, Z.; Mathur, J.; Kauschmann, A.; Altmann, T.; Rédei, G.P.; Nagy, F.; Schell, J.; Koncz, C. Brassinosteroids rescue the deficiency of CYP90, a cytochrome P450, controlling cell elongation and de-etiolation in Arabidopsis. Cell 1996, 85, 171-182. [CrossRef]

116. Talon, M.; Koornneef, M.; Zeevaart, J.A. Endogenous gibberellins in Arabidopsis thaliana and possible steps blocked in the biosynthetic pathways of the semidwarf ga4 and ga5 mutants. Proc. Natl. Acad. Sci. USA 1990, 87, 7983-7987. [CrossRef] 
117. Wilson, R.N.; Somerville, C.R. Phenotypic Suppression of the Gibberellin-Insensitive Mutant (gai) of Arabidopsis. Plant Physiol. 1995, 108, 495-502. [CrossRef]

118. Jager, C.E.; Symons, G.M.; Ross, J.J.; Smith, J.J.; Reid, J.B. The brassinosteroid growth response in pea is not mediated by changes in gibberellin content. Planta 2005, 221, 141-148. [CrossRef] [PubMed]

119. Katsumi, M. Interaction of a Brassinosteroid with IAA and GA3 in the Elongation of Cucumber Hypocotyl Sections. Plant Cell Physiol. 1985, 26, 615-625. [CrossRef]

120. Yang, G.X.; Jan, A.; Shen, S.H.; Yazaki, J.; Ishikawa, M.; Shimatani, Z.; Kishimoto, N.; Kikuchi, S.; Matsumoto, H.; Komatsu, S. Microarray analysis of brassinosteroids- and gibberellin-regulated gene expression in rice seedlings. Mol. Genet. Genom. 2004, 271, 468-478. [CrossRef] [PubMed]

121. Tanaka, K.; Nakamura, Y.; Asami, T.; Yoshida, S.; Matsuo, T.; Okamoto, S. Physiological Roles of Brassinosteroids in Early Growth of Arabidopsis: Brassinosteroids Have a Synergistic Relationship with Gibberellin as well as Auxin in Light-Grown Hypocotyl Elongation. J. Plant Growth Regul. 2003, 22, 259-271. [CrossRef]

122. Bai, M.-Y.; Shang, J.-X.; Oh, E.; Fan, M.; Bai, Y.; Zentella, R.; Sun, T.; Wang, Z.-Y. Brassinosteroid, gibberellin and phytochrome impinge on a common transcription module in Arabidopsis. Nat. Cell Biol. 2012, 14, 810-817. [CrossRef] [PubMed]

123. Gallego-Bartolome, J.; Minguet, E.G.; Grau-Enguix, F.; Abbas, M.; Locascio, A.; Thomas, S.G.; Alabadi, D.; Blazquez, M.A. Molecular mechanism for the interaction between gibberellin and brassinosteroid signaling pathways in Arabidopsis. Proc. Natl. Acad. Sci. USA 2012, 109, 13446-13451. [CrossRef]

124. Li, Q.F.; Wang, C.; Jiang, L.; Li, S.; Sun, S.S.M.; He, J.X. An interaction between BZR1 and DELLAs mediates direct signaling crosstalk between brassinosteroids and gibberellins in Arabidopsis. Sci. Signal. 2012, 5, ra72. [CrossRef]

125. Stewart Lilley, J.L.; Gan, Y.; Graham, I.A.; Nemhauser, J.L. The effects of DELLAs on growth change with developmental stage and brassinosteroid levels. Plant J. 2013, 76, 165-173. [CrossRef]

126. Unterholzner, S.J.; Rozhon, W.; Papacek, M.; Ciomas, J.; Lange, T.; Kugler, K.G.; Mayer, K.F.; Sieberer, T.; Poppenberger, B. Brassinosteroids Are Master Regulators of Gibberellin Biosynthesis in Arabidopsis. Plant Cell 2015, 27, 2261-2272. [CrossRef]

127. Tong, H.; Xiao, Y.; Liu, D.; Gao, S.; Liu, L.; Yin, Y.; Jin, Y.; Qian, Q.; Chu, C. Brassinosteroid Regulates Cell Elongation by Modulating Gibberellin Metabolism in Rice. Plant Cell Online 2014, 26, 4376-4393. [CrossRef]

128. Ross, J.J.; Quittenden, L.J. Interactions between Brassinosteroids and Gibberellins: Synthesis or Signaling? Plant Cell 2016, 28, 829-832. [CrossRef] [PubMed]

129. Tong, H.; Chu, C. Reply: Brassinosteroid Regulates Gibberellin Synthesis to Promote Cell Elongation in Rice: Critical Comments on Ross and Quittenden's Letter. Plant Cell 2016, 28, 833-835. [CrossRef]

130. Unterholzner, S.J.; Rozhon, W.; Poppenberger, B. REPLY: Interaction Between Brassinosteroids and Gibberellins: Synthesis or Signaling? In Arabidopsis, Both! Plant Cell 2016, 28, 836-839. [CrossRef] [PubMed]

131. Allen, H.R.; Ptashnyk, M. Mathematical modelling and analysis of the brassinosteroid and gibberellin signalling pathways and their interactions. J. Theor. Biol. 2017, 432, 109-131. [CrossRef] [PubMed]

132. De Vleesschauwer, D.; Van Buyten, E.; Satoh, K.; Balidion, J.; Mauleon, R.; Choi, I.-R.; Vera-Cruz, C.; Kikuchi, S.; Hofte, M. Brassinosteroids Antagonize Gibberellin- and Salicylate-Mediated Root Immunity in Rice. Plant Physiol. 2012, 158, 1833-1846. [CrossRef] [PubMed]

133. Schmitz, A.J.; Folsom, J.J.; Jikamaru, Y.; Ronald, P.; Walia, H. SUB1A-mediated submergence tolerance response in rice involves differential regulation of the brassinosteroid pathway. New Phytol. 2013, 198, 1060-1070. [CrossRef] [PubMed]

134. Achard, P.; Renou, J.P.; Berthomé, R.; Harberd, N.P.; Genschik, P. Plant DELLAs Restrain Growth and Promote Survival of Adversity by Reducing the Levels of Reactive Oxygen Species. Curr. Biol. 2008, 18, 656-660. [CrossRef]

135. Werner, T.; Schmülling, T. Cytokinin action in plant development. Curr. Opin. Plant Biol. 2009, 12, 527-538. [CrossRef]

136. Werner, T.; Nehnevajova, E.; Köllmer, I.; Novák, O.; Strnad, M.; Krämer, U.; Schmülling, T. Root-Specific Reduction of Cytokinin Causes Enhanced Root Growth, Drought Tolerance, and Leaf Mineral Enrichment in Arabidopsis and Tobacco. Plant Cell 2010, 22, 3905-3920. [CrossRef] 
137. Nishiyama, R.; Watanabe, Y.; Fujita, Y.; Le, D.T.; Kojima, M.; Werner, T.; Vankova, R.; Yamaguchi-Shinozaki, K.; Shinozaki, K.; Kakimoto, T.; et al. Analysis of Cytokinin Mutants and Regulation of Cytokinin Metabolic Genes Reveals Important Regulatory Roles of Cytokinins in Drought, Salt and Abscisic Acid Responses, and Abscisic Acid Biosynthesis. Plant Cell 2011, 23, 2169-2183. [CrossRef]

138. Vercruyssen, L.; Gonzalez, N.; Werner, T.; Schmulling, T.; Inze, D. Combining Enhanced Root and Shoot Growth Reveals Cross Talk between Pathways That Control Plant Organ Size in Arabidopsis. Plant Physiol. 2011, 155, 1339-1352. [CrossRef] [PubMed]

139. Yuan, L.B.; Peng, Z.H.; Zhi, T.T.; Zho, Z.; Liu, Y.; Zhu, Q.; Xiong, X.Y.; Ren, C.M. Brassinosteroid enhances cytokinin-induced anthocyanin biosynthesis in Arabidopsis seedlings. Biol. Plant. 2014, 59, 99-105. [CrossRef]

140. Tran, L.-S.P.; Urao, T.; Qin, F.; Maruyama, K.; Kakimoto, T.; Shinozaki, K.; Yamaguchi-Shinozaki, K. Functional analysis of AHK1/ATHK1 and cytokinin receptor histidine kinases in response to abscisic acid, drought, and salt stress in Arabidopsis. Proc. Natl. Acad. Sci. USA 2007, 104, 20623-20628. [CrossRef] [PubMed]

141. Havlová, M.; Dobrev, P.I.; Motyka, V.; Štorchová, H.; Libus, J.; Dobrá, J.; Malbeck, J.; Gaudinová, A.; Vanková, R. The role of cytokinins in responses to water deficit in tobacco plants over-expressing trans-zeatin O-glucosyltransferase gene under 35S or SAG12 promoters. Plant Cell Environ. 2008, 31, 341-353. [CrossRef] [PubMed]

142. Argueso, C.T.; Ferreira, F.J.; Kieber, J.J. Environmental perception avenues: The interaction of cytokinin and environmental response pathways. Plant Cell Environ. 2009, 32, 1147-1160. [CrossRef] [PubMed]

143. Nishiyama, R.; Le, D.T.; Watanabe, Y.; Matsui, A.; Tanaka, M.; Seki, M.; Yamaguchi-Shinozaki, K.; Shinozaki, K.; Tran, L.S.P. Transcriptome analyses of a salt-tolerant cytokinin-deficient mutant reveal differential regulation of salt stress response by cytokinin deficiency. PLoS ONE 2012, 7, e32124. [CrossRef] [PubMed]

144. Peleg, Z.; Reguera, M.; Tumimbang, E.; Walia, H.; Blumwald, E. Cytokinin-mediated source/sink modifications improve drought tolerance and increase grain yield in rice under water-stress. Plant Biotechnol. J. 2011, 9, 747-758. [CrossRef] [PubMed]

145. Roitsch, T.; Ehneß, R. Regulation of source/sink relations by cytokinins. Plant Growth Regul. 2000, 32, 359-367. [CrossRef]

146. Vahala, J.; Schlagnhaufer, C.D.; Pell, E.J. Induction of an ACC synthase cDNA by ozone in light-grown Arabidopsis thaliana leaves. Physiol. Plant. 1998, 103, 45-50. [CrossRef]

147. Khripach, V.; Zhabinskii, V.; De Groot, A. Twenty years of brassinosteroids: Steroidal plant hormones warrant better crops for the XXI century. Ann. Bot. 2000, 86, 441-447. [CrossRef]

148. Choe, S.; Fujioka, S.; Noguchi, T.; Takatsuto, S.; Yoshida, S.; Feldmann, K.A. Overexpression of DWARF4 in the brassinosteroid biosynthetic pathway results in increased vegetative growth and seed yield in Arabidopsis. Plant J. 2001, 26, 573-582. [CrossRef] [PubMed]

149. Sakamoto, T.; Morinaka, Y.; Ohnishi, T.; Sunohara, H.; Fujioka, S.; Ueguchi-Tanaka, M.; Mizutani, M.; Sakata, K.; Takatsuto, S.; Yoshida, S.; et al. Erect leaves caused by brassinosteroid deficiency increase biomass production and grain yield in rice. Nat. Biotechnol. 2006, 24, 105-109. [CrossRef]

150. Morinaka, Y.; Sakamoto, T.; Inukai, Y.; Agetsuma, M.; Kitano, H.; Ashikari, M.; Matsuoka, M. Morphological alteration caused by brassinosteroid insensitivity increases the biomass and grain production of rice. Plant Physiol. 2006, 141, 924-931. [CrossRef] [PubMed]

151. Sahni, S.; Prasad, B.D.; Liu, Q.; Grbic, V.; Sharpe, A.; Singh, S.P.; Krishna, P. Overexpression of the brassinosteroid biosynthetic gene DWF4 in Brassica napus simultaneously increases seed yield and stress tolerance. Sci. Rep. 2016, 6, 28298. [CrossRef] [PubMed]

152. Li, Q.-F.; Yu, J.-W.; Lu, J.; Fei, H.-Y.; Luo, M.; Cao, B.-W.; Huang, L.-C.; Zhang, C.-Q.; Liu, Q.-Q. Seed-Specific Expression of OsDWF4, a Rate-Limiting Gene Involved in Brassinosteroids Biosynthesis, Improves Both Grain Yield and Quality in Rice. J. Agric. Food Chem. 2018, 66, 3759-3772. [CrossRef] [PubMed]

153. Zhang, S.; Cai, Z.; Wang, X. The primary signaling outputs of brassinosteroids are regulated by abscisic acid signaling. Proc. Natl. Acad. Sci. USA 2009, 106, 4543-4548. [CrossRef] [PubMed]

154. Abeles, F.B.; Morgan, P.W.; Salveit, M.E. Ethylene in Plant Biology, 2nd ed.; Academic Press, Inc.: San Diego, CA, USA, 1992; ISBN 0-12-041451-1.

155. Yang, S.F.; Hoffman, N.E. Ethylene biosynthesis and its regulation inhi gher plants. Annu. Rev. Plant Physiol. 1984, 35, 155-189. [CrossRef] 
156. Hansen, M.; Chae, H.S.; Kieber, J.J. Regulation of ACS protein stability by cytokinin and brassinosteroid. Plant J. 2009, 57, 606-614. [CrossRef]

157. Zimmermann, P. GENEVESTIGATOR. Arabidopsis Microarray Database and Analysis Toolbox. Plant Physiol. 2004, 136, 2621-2632. [CrossRef]

158. Lv, B.; Tian, H.; Zhang, F.; Liu, J.; Lu, S.; Bai, M.; Li, C.; Ding, Z. Brassinosteroids regulate root growth by controlling reactive oxygen species homeostasis and dual effect on ethylene synthesis in Arabidopsis. PLoS Genet. 2018, 14, e1007144. [CrossRef]

159. Guo, Y.; Shan, W.; Liang, S.; Wu, C.; Wei, W.; Chen, J.; Lu, W.; Kuang, J. MaBZR1/2 act as transcriptional repressors of ethylene biosynthetic genes in banana fruit. Physiol. Plant. 2018. [CrossRef] [PubMed]

160. Zhu, T.; Tan, W.R.; Deng, X.G.; Zheng, T.; Zhang, D.W.; Lin, H.H. Effects of brassinosteroids on quality attributes and ethylene synthesis in postharvest tomato fruit. Postharvest Biol. Technol. 2015, 100, 196-204. [CrossRef]

161. Li, Q.F.; He, J.X. BZR1 Interacts with HY5 to Mediate Brassinosteroid- and Light-Regulated Cotyledon Opening in Arabidopsis in Darkness. Mol. Plant 2016, 9, 113-125. [CrossRef]

162. Nie, S.; Huang, S.; Wang, S.; Cheng, D.; Liu, J.; Lv, S.; Li, Q.; Wang, X. Enhancing Brassinosteroid Signaling via Overexpression of Tomato (Solanum lycopersicum) SIBRI1 Improves Major Agronomic Traits. Front. Plant Sci. 2017, 8, 1386. [CrossRef]

163. Zhu, T.; Deng, X.; Zhou, X.; Zhu, L.; Zou, L.; Li, P.; Zhang, D.; Lin, H. Ethylene and hydrogen peroxide are involved in brassinosteroid-induced salt tolerance in tomato. Sci. Rep. 2016, 6, 35392. [CrossRef]

164. Larkindale, J.; Hall, J.D.; Knight, M.R.; Vierling, E.; Larkindale, J.; Hall, J.D.; Knight, M.R.; Vierling, E. Heat Stress Phenotypes of Arabidopsis Mutants Implicate Multiple Signaling Pathways in the Acquisition of Thermotolerance. Plant Physiol. 2018, 138, 882-897. [CrossRef]

165. Bari, R.; Jones, J.D.G. Role of plant hormones in plant defence responses. Plant Mol. Biol. 2009, 69, $473-488$. [CrossRef]

166. Divi, U.K.; Rahman, T.; Krishna, P. Brassinosteroid-mediated stress tolerance in Arabidopsis shows interactions with abscisic acid, ethylene and salicylic acid pathways. BMC Plant Biol. 2010, 10, 151. [CrossRef]

167. Serna, M.; Coll, Y.; Zapata, P.J.; Botella, M.Á.; Pretel, M.T.; Amorós, A. A brassinosteroid analogue prevented the effect of salt stress on ethylene synthesis and polyamines in lettuce plants. Sci. Hortic. 2015, 185, 105-112. [CrossRef]

168. Mayak, S.; Tirosh, T.; Glick, B.R. Plant growth-promoting bacteria confer resistance in tomato plants to salt stress. Plant Physiol. Biochem. 2004, 42, 565-572. [CrossRef]

169. Mustilli, A.-C.; Merlot, S.; Vavasseur, A.; Fenzi, F.; Giraudat, J. Arabidopsis OST1 Protein Kinase Mediates the Regulation of Stomatal Aperture by Abscisic Acid and Acts Upstream of Reactive Oxygen Species Production. Plant Cell Online 2002, 14, 3089-3099. [CrossRef]

170. Yoshida, R.; Hobo, T.; Ichimura, K.; Mizoguchi, T.; Takahashi, F.; Aronso, J.; Ecker, J.R.; Shinozaki, K. ABA-activated SnRK2 protein kinase is required for dehydration stress signaling in Arabidopsis. Plant Cell Physiol. 2002, 43, 1473-1483. [CrossRef]

171. Yoshida, R.; Umezawa, T.; Mizoguchi, T.; Takahashi, S.; Takahashi, F.; Shinozaki, K. The regulatory domain of SRK2E/OST1/SnRK2.6 interacts with ABI1 and integrates abscisic acid (ABA) and osmotic stress signals controlling stomatal closure in Arabidopsis. J. Biol. Chem. 2006, 281, 5310-5318. [CrossRef] [PubMed]

172. Fujii, H.; Verslues, P.E.; Zhu, J.-K. Identification of Two Protein Kinases Required for Abscisic Acid Regulation of Seed Germination, Root Growth, and Gene Expression in Arabidopsis. Plant Cell Online 2007, 19, 485-494. [CrossRef] [PubMed]

173. Fujii, H.; Zhu, J.-K. Arabidopsis mutant deficient in 3 abscisic acid-activated protein kinases reveals critical roles in growth, reproduction, and stress. Proc. Natl. Acad. Sci. USA 2009, 106, 8380-8385. [CrossRef]

174. Umezawa, T.; Nakashima, K.; Miyakawa, T.; Kuromori, T.; Tanokura, M.; Shinozaki, K.; YamaguchiShinozaki, K. Molecular basis of the core regulatory network in ABA responses: Sensing, signaling and transport. Plant Cell Physiol. 2010, 51, 1821-1839. [CrossRef] [PubMed]

175. Fujii, H.; Chinnusamy, V.; Rodrigues, A.; Rubio, S.; Antoni, R.; Park, S.-Y.; Cutler, S.R.; Sheen, J.; Rodriguez, P.L.; Zhu, J.-K. In vitro reconstitution of an abscisic acid signalling pathway. Nature 2009, 462, 660-664. [CrossRef] [PubMed] 
176. Fujita, Y.; Nakashima, K.; Yoshida, T.; Katagiri, T.; Kidokoro, S.; Kanamori, N.; Umezawa, T.; Fujita, M.; Maruyama, K.; Ishiyama, K.; et al. Three SnRK2 protein kinases are the main positive regulators of abscisic acid signaling in response to water stress in Arabidopsis. Plant Cell Physiol. 2009, 50, 2123-2132. [CrossRef] [PubMed]

177. Nakashima, K.; Fujita, Y.; Kanamori, N.; Katagiri, T.; Umezawa, T.; Kidokoro, S.; Maruyama, K.; Yoshida, T.; Ishiyama, K.; Kobayashi, M.; et al. Three Arabidopsis SnRK2 protein kinases, SRK2D/SnRK2.2, SRK2E/SnRK2.6/OST1 and SRK2I/SnRK2.3, involved in ABA signaling are essential for the control of seed development and dormancy. Plant Cell Physiol. 2009, 50, 1345-1363. [CrossRef] [PubMed]

178. Umezawa, T.; Sugiyama, N.; Mizoguchi, M.; Hayashi, S.; Myouga, F.; Yamaguchi-Shinozaki, K.; Ishihama, Y.; Hirayama, T.; Shinozaki, K. Type 2C protein phosphatases directly regulate abscisic acid-activated protein kinases in Arabidopsis. Proc. Natl. Acad. Sci. USA 2009, 106, 17588-17593. [CrossRef] [PubMed]

179. Ma, Y.; Szostkiewicz, I.; Korte, A.; Moes, D.; Yang, Y.; Christmann, A.; Grill, E. Regulators of PP2C phosphatase activity function as abscisic acid sensors. Science 2009, 324, 1064-1068. [CrossRef] [PubMed]

180. Park, S.Y.; Fung, P.; Nishimura, N.; Jensen, D.R.; Fujii, H.; Zhao, Y.; Lumba, S.; Santiago, J.; Rodrigues, A.; Chow, T.F.F.; et al. Abscisic acid inhibits type $2 \mathrm{C}$ protein phosphatases via the PYR/PYL family of START proteins. Science 2009, 324, 1068-1071. [CrossRef] [PubMed]

181. Miyazono, K.; Miyakawa, T.; Sawano, Y.; Kubota, K.; Kang, H.-J.; Asano, A.; Miyauchi, Y.; Takahashi, M.; Zhi, Y.; Fujita, Y.; et al. Structural basis of abscisic acid signalling. Nature 2009, 462, 609-614. [CrossRef] [PubMed]

182. Melcher, K.; Ng, L.M.; Zhou, X.E.; Soon, F.F.; Xu, Y.; Suino-Powell, K.M.; Park, S.Y.; Weiner, J.J.; Fujii, H.; Chinnusamy, V.; et al. A gate-latch-lock mechanism for hormone signalling by abscisic acid receptors. Nature 2009, 462, 602-608. [CrossRef] [PubMed]

183. Yin, P.; Fan, H.; Hao, Q.; Yuan, X.; Wu, D.; Pang, Y.; Yan, C.; Li, W.; Wang, J.; Yan, N. Structural insights into the mechanism of abscisic acid signaling by PYL proteins. Nat. Struct. Mol. Biol. 2009, 16, 1230-1236. [CrossRef] [PubMed]

184. Arc, E.; Sechet, J.; Corbineau, F.; Rajjou, L.; Marion-Poll, A. ABA crosstalk with ethylene and nitric oxide in seed dormancy and germination. Front. Plant Sci. 2013, 4. [CrossRef]

185. Daszkowska-Golec, A.; Szarejko, I. Open or Close the Gate-Stomata Action under the Control of Phytohormones in Drought Stress Conditions. Front. Plant Sci. 2013, 4, 138. [CrossRef] [PubMed]

186. O’Brien, J.A.; Benková, E. Cytokinin cross-talking during biotic and abiotic stress responses. Front. Plant Sci. 2013, 4, 451. [CrossRef]

187. Steber, C.M.; McCourt, P. A role for brassinosteroids in germination in Arabidopsis. Plant Physiol. 2001, 125, 763-769. [CrossRef]

188. Rodrigues, A.; Santiago, J.; Rubio, S.; Saez, A.; Osmont, K.S.; Gadea, J.; Hardtke, C.S.; Rodriguez, P.L. The Short-Rooted Phenotype of the brevis radix Mutant Partly Reflects Root Abscisic Acid Hypersensitivity. Plant Physiol. 2009, 149, 1917-1928. [CrossRef]

189. Li, J.; Nam, K.H.; Vafeados, D.; Chory, J. BIN2, a new brassinosteroid-insensitive locus in Arabidopsis. Plant Physiol. 2001, 127, 14-22. [CrossRef] [PubMed]

190. Belkhadir, Y.; Jaillais, Y. The molecular circuitry of brassinosteroid signaling. New Phytol. 2015, 206, 522-540. [CrossRef] [PubMed]

191. Cai, Z.; Liu, J.; Wang, H.; Yang, C.; Chen, Y.; Li, Y.; Pan, S.; Dong, R.; Tang, G.; de Dios Barajas-Lopez, J.; et al. GSK3-like kinases positively modulate abscisic acid signaling through phosphorylating subgroup III SnRK2s in Arabidopsis. Proc. Natl. Acad. Sci. USA 2014, 111, 9651-9656. [CrossRef] [PubMed]

192. Lopez-Molina, L.; Mongrand, S.; McLachlin, D.T.; Chait, B.T.; Chua, N.H. ABI5 acts downstream of ABI3 to execute an ABA-dependent growth arrest during germination. Plant J. 2002, 32, 317-328. [CrossRef] [PubMed]

193. Lopez-Molina, L.; Mongrand, S.; Chua, N.-H. A postgermination developmental arrest checkpoint is mediated by abscisic acid and requires the ABI5 transcription factor in Arabidopsis. Proc. Natl. Acad. Sci. USA 2001, 98, 4782-4787. [CrossRef] [PubMed]

194. Finkelstein, R.R. The Arabidopsis Abscisic Acid Response Gene ABI5 Encodes a Basic Leucine Zipper Transcription Factor. Plant Cell Online 2000, 12, 599-610. [CrossRef] 
195. Hu, Y.; Yu, D. BRASSINOSTEROID INSENSITIVE2 Interacts with ABSCISIC ACID INSENSITIVE5 to Mediate the Antagonism of Brassinosteroids to Abscisic Acid during Seed Germination in Arabidopsis. Plant Cell Online 2014, 26, 4394-4408. [CrossRef]

196. Wang, H.; Tang, J.; Liu, J.; Hu, J.; Liu, J.; Chen, Y.; Cai, Z.; Wang, X. Abscisic Acid Signaling Inhibits Brassinosteroid Signaling through Dampening the Dephosphorylation of BIN2 by ABI1 and ABI2. Mol. Plant 2018, 11, 315-325. [CrossRef]

197. Shang, Y.; Dai, C.; Lee, M.M.; Kwak, J.M.; Nam, K.H. BRI1-Associated Receptor Kinase 1 Regulates Guard Cell ABA Signaling Mediated by Open Stomata 1 in Arabidopsis. Mol. Plant 2016, 9, 447-460. [CrossRef]

198. Ryu, H.; Cho, H.; Bae, W.; Hwang, I. Control of early seedling development by BES1/TPL/HDA19-mediated epigenetic regulation of ABI3. Nat. Commun. 2014, 5, 4138. [CrossRef]

199. Yang, X.; Bai, Y.; Shang, J.; Xin, R.; Tang, W. The antagonistic regulation of abscisic acid-inhibited root growth by brassinosteroids is partially mediated via direct suppression of ABSCISIC ACID INSENSITIVE 5 expression by BRASSINAZOLE RESISTANT 1. Plant Cell Environ. 2016, 39, 1994-2003. [CrossRef] [PubMed]

200. Ng, L.-M.; Soon, F.-F.; Zhou, X.E.; West, G.M.; Kovach, A.; Suino-Powell, K.M.; Chalmers, M.J.; Li, J.; Yong, E.-L.; Zhu, J.-K.; et al. Structural basis for basal activity and autoactivation of abscisic acid (ABA) signaling SnRK2 kinases. Proc. Natl. Acad. Sci. USA 2011, 108, 21259-21264. [CrossRef]

201. Belin, C.; de Franco, P.-O.; Bourbousse, C.; Chaignepain, S.; Schmitter, J.-M.; Vavasseur, A.; Giraudat, J.; Barbier-Brygoo, H.; Thomine, S. Identification of features regulating OST1 kinase activity and OST1 function in guard cells. Plant Physiol. 2006, 141, 1316-1327. [CrossRef]

202. Yunta, C.; Martínez-Ripoll, M.; Zhu, J.K.; Albert, A. The structure of Arabidopsis thaliana OST1 provides insights into the kinase regulation mechanism in response to osmotic stress. J. Mol. Biol. 2011, 414, 135-144. [CrossRef]

203. Wang, Z.-Y. Brassinosteroids modulate plant immunity at multiple levels. Proc. Natl. Acad. Sci. USA 2012, 109, 7-8. [CrossRef] [PubMed]

204. Tena, G.; Boudsocq, M.; Sheen, J. Protein kinase signaling networks in plant innate immunity. Curr. Opin. Plant Biol. 2011, 14, 519-529. [CrossRef] [PubMed]

205. McCann, H.C.; Nahal, H.; Thakur, S.; Guttman, D.S. Identification of innate immunity elicitors using molecular signatures of natural selection. Proc. Natl. Acad. Sci. USA 2012, 109, 4215-4220. [CrossRef]

206. Spoel, S.H.; Dong, X. How do plants achieve immunity? Defence without specialized immune cells. Nat. Rev. Immunol. 2012, 12, 89-100. [CrossRef]

207. Nakashita, H.; Yasuda, M.; Nitta, T.; Asami, T.; Fujioka, S.; Arai, Y.; Sekimata, K.; Takatsuto, S.; Yamaguchi, I.; Yoshida, S. Brassinosteriod functions in a broad range of disease resistance in tobacco and rice. Plant J. 2003, 33, 887-898. [CrossRef]

208. Chinchilla, D.; Shan, L.; He, P.; de Vries, S.; Kemmerling, B. One for all: The receptor-associated kinase BAK1. Trends Plant Sci. 2009, 14, 535-541. [CrossRef]

209. Chinchilla, D.; Zipfel, C.; Robatzek, S.; Kemmerling, B.; Nürnberger, T.; Jones, J.D.G.; Felix, G.; Boller, T. A flagellin-induced complex of the receptor FLS2 and BAK1 initiates plant defence. Nature 2007, 448, 497-500. [CrossRef]

210. Heese, A.; Hann, D.R.; Gimenez-Ibanez, S.; Jones, A.M.E.; He, K.; Li, J.; Schroeder, J.I.; Peck, S.C.; Rathjen, J.P. The receptor-like kinase SERK3/BAK1 is a central regulator of innate immunity in plants. Proc. Natl. Acad. Sci. USA 2007, 104, 12217-12222. [CrossRef]

211. Segonzac, C.; Zipfel, C. Activation of plant pattern-recognition receptors by bacteria. Curr. Opin. Microbiol. 2011, 14, 54-61. [CrossRef]

212. Lu, D.; Wu, S.; Gao, X.; Zhang, Y.; Shan, L.; He, P. A receptor-like cytoplasmic kinase, BIK1, associates with a flagellin receptor complex to initiate plant innate immunity. Proc. Natl. Acad. Sci. USA 2010, 107, 496-501. [CrossRef]

213. Zhang, J.; Li, W.; Xiang, T.; Liu, Z.; Laluk, K.; Ding, X.; Zou, Y.; Gao, M.; Zhang, X.; Chen, S.; et al. Receptor-like cytoplasmic kinases integrate signaling from multiple plant immune receptors and are targeted by a Pseudomonas syringae effector. Cell Host Microbe 2010, 7, 290-301. [CrossRef]

214. Albrecht, C.; Boutrot, F.; Segonzac, C.; Schwessinger, B.; Gimenez-Ibanez, S.; Chinchilla, D.; Rathjen, J.P.; de Vries, S.C.; Zipfel, C. Brassinosteroids inhibit pathogen-associated molecular pattern-triggered immune signaling independent of the receptor kinase BAK1. Proc. Natl. Acad. Sci. USA 2012, 109, 303-308. [CrossRef] 
215. Belkhadir, Y.; Jaillais, Y.; Epple, P.; Balsemao-Pires, E.; Dangl, J.L.; Chory, J. Brassinosteroids modulate the efficiency of plant immune responses to microbe-associated molecular patterns. Proc. Natl. Acad. Sci. USA 2012, 109, 297-302. [CrossRef]

216. Grant, M.R.; Jones, J.D.G.; Science, S.; Series, N.; May, N. Plant-Microbe Interactions Hormone (Dis) Harmony Moulds Plant Health and Disease. Science 2009, 324, 750-752. [CrossRef]

217. Robert-Seilaniantz, A.; Grant, M.; Jones, J.D.G. Hormone Cross-talk in Plant Disease and Defense: More Than Just JASMONATE-SALICYLATE Antagonism. Annu. Rev. Phytopathol. 2011, 49, 317-343. [CrossRef]

218. Koornneef, A.; Pieterse, C.M.J. Cross Talk in Defense Signaling. Plant Physiol. 2008, 146, 839-844. [CrossRef]

219. Pieterse, C.M.J.; Leon-Reyes, A.; Van Der Ent, S.; Van Wees, S.C.M. Networking by small-molecule hormones in plant immunity. Nat. Chem. Biol. 2009, 5, 308-316. [CrossRef]

220. Thaler, J.S.; Humphrey, P.T.; Whiteman, N.K. Evolution of jasmonate and salicylate signal. Trends Plant Sci. 2012, 17, 260-270. [CrossRef]

221. Zhou, G.; Qi, J.; Ren, N.; Cheng, J.; Erb, M.; Mao, B.; Lou, Y. Silencing OsHI-LOX makes rice more susceptible to chewing herbivores, but enhances resistance to a phloem feeder. Plant J. 2009, 60, 638-648. [CrossRef]

222. Zhou, G.; Ren, N.; Qi, J.; Lu, J.; Xiang, C.; Ju, H.; Cheng, J.; Lou, Y. The 9-lipoxygenase Osr9-LOX1 interacts with the 13-lipoxygenase-mediated pathway to regulate resistance to chewing and piercing-sucking herbivores in rice. Physiol. Plant. 2014, 152, 59-69. [CrossRef]

223. Tamaoki, D.; Seo, S.; Yamada, S.; Kano, A.; Miyamoto, A.; Shishido, H.; Miyoshi, S.; Taniguch, S.; Akimitsu, K.; Gomi, K. Jasmonic acid and salicylic acid activate a common defense system in rice. Plant Signal. Behav. 2013, 8, e24260. [CrossRef]

224. Pan, G.; Liu, Y.; Ji, L.; Zhang, X.; He, J.; Huang, J.; Qiu, Z.; Liu, D.; Sun, Z.; Xu, T.; et al. Brassinosteroids Mediate Susceptibility to Brown Planthopper by Integrating with Salicylic Acid and Jasmonic Acid Pathways in Rice. J. Exp. Bot. 2018, 69, 4433-4442. [CrossRef]

225. Campos, M.L.; De Almeida, M.; Rossi, M.L.; Martinelli, A.P.; Litholdo Junior, C.G.; Figueira, A.; RampelottiFerreira, F.T.; Vendramim, J.D.; Benedito, V.A.; Pereira Peres, L.E. Brassinosteroids interact negatively with jasmonates in the formation of anti-herbivory traits in tomato. J. Exp. Bot. 2009, 60, 4347-4361. [CrossRef]

226. He, Y.; Zhang, H.; Sun, Z.; Li, J.; Hong, G.; Zhu, Q.; Zhou, X.; MacFarlane, S.; Yan, F.; Chen, J. Jasmonic acid-mediated defense suppresses brassinosteroid-mediated susceptibility to Rice black streaked dwarf virus infection in rice. New Phytol. 2017, 214, 388-399. [CrossRef]

227. Miyaji, T.; Yamagami, A.; Kume, N.; Sakuta, M.; Osada, H.; Asami, T.; Arimoto, Y.; Nakano, T. Brassinosteroidrelated transcription factor BIL1/BZR1 increases plant resistance to insect feeding. Biosci. Biotechnol. Biochem. 2014, 78, 960-968. [CrossRef]

228. Yang, D.H.; Baldwin, I.T.; Wu, J. Silencing Brassinosteroid Receptor BRI1 Impairs Herbivory-elicited Accumulation of Jasmonic Acid-isoleucine and Diterpene Glycosides, but not Jasmonic Acid and Trypsin Proteinase Inhibitors in Nicotiana attenuata. J. Integr. Plant Biol. 2013, 55, 514-526. [CrossRef]

229. Huot, B.; Yao, J.; Montgomery, B.L.; He, S.Y. Growth-defense tradeoffs in plants: A balancing act to optimize fitness. Mol. Plant 2014, 7, 1267-1287. [CrossRef]

230. Beveridge, C.A.; Kyozuka, J. New genes in the strigolactone-related shoot branching pathway. Curr. Opin. Plant Biol. 2010, 13, 34-39. [CrossRef]

231. Wang, Y.; Sun, S.; Zhu, W.; Jia, K.; Yang, H.; Wang, X. Strigolactone/MAX2-Induced Degradation of Brassinosteroid Transcriptional Effector BES1 Regulates Shoot Branching. Dev. Cell 2013, 27, 681-688. [CrossRef]

(C) 2019 by the authors. Licensee MDPI, Basel, Switzerland. This article is an open access article distributed under the terms and conditions of the Creative Commons Attribution (CC BY) license (http:/ / creativecommons.org/licenses/by/4.0/). 